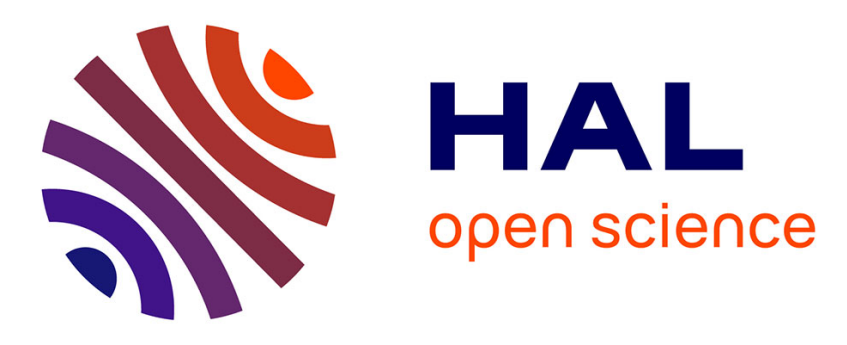

\title{
Topological Features of both Electron Density and Electrostatic Potential in Bis(tiosemicarbazide)zinc(II) dinitrate Complex
}

Sladjana B. Novakovi\&\#263, Goran A. Bogdanović, Bernard Fraisse, Nour Eddine Ghermani, Nouzha Bouhmaida, Anne Spasojevic - de Biré

\section{To cite this version:}

Sladjana B. Novakovi\&\#263, Goran A. Bogdanović, Bernard Fraisse, Nour Eddine Ghermani, Nouzha Bouhmaida, et al.. Topological Features of both Electron Density and Electrostatic Potential in Bis(tiosemicarbazide)zinc(II) dinitrate Complex. Journal of Physical Chemistry A, 2007, 111 (51), pp.13492 -13505. 10.1021/jp075456i . hal-00204137v2

\section{HAL Id: hal-00204137 \\ https://hal.science/hal-00204137v2}

Submitted on 29 Sep 2020

HAL is a multi-disciplinary open access archive for the deposit and dissemination of scientific research documents, whether they are published or not. The documents may come from teaching and research institutions in France or abroad, or from public or private research centers.
L'archive ouverte pluridisciplinaire HAL, est destinée au dépôt et à la diffusion de documents scientifiques de niveau recherche, publiés ou non, émanant des établissements d'enseignement et de recherche français ou étrangers, des laboratoires publics ou privés. 


\section{Topological Features of both Electron Density and}

\section{Electrostatic Potential in Bis(tiosemicarbazide)zinc(II)}

\section{dinitrate Complex}

Sladjana B. Novaković ${ }^{1}$, Goran A. Bogdanović ${ }^{* 1}$, Bernard Fraisse ${ }^{2}$, Nour Eddine Ghermani ${ }^{2,3}$, Nouzha Bouhmaida ${ }^{4}$ and Anne Spasojević-de Biré**²

1. "VINČA" Institute of Nuclear Sciences, Laboratory of Theoretical Physics and Condensed Matter Physics, PO Box 522, 11001 Belgrade, Serbia

2. Laboratoire "Structures Propriétés et Modélisation des Solides”, UMR CNRS 8580, Ecole Centrale Paris, Grande Voie des Vignes 92295 Châtenay-Malabry Cedex, France

3. Laboratoire "Physico-Chimie, Pharmacotechnie et Biopharmacie", UMR CNRS 8612, IFR 141, Faculté de Pharmacie, Université Paris-Sud, 5 rue Jean-Baptiste Clément, 92296 Châtenay-Malabry Cedex, France

4. Laboratoire "Sciences des Matériaux", LSM, Université Cadi Ayyad, Faculté des Sciences Semlalia, Boulevard Prince Moulay Abdallah, BP 2390, 40000 Marrakech, Morocco

*E-mail: goranb@vin.bg.ac.yu;

*Phone: +381-11-8065-828; Fax: +381-11-8065-829

**E-mail: anne.spasojevic@ecp.fr

**Phone : 3314113 15 90; Fax: 33141131437 


\section{Abstract}

The experimental electron density of bis(tiosemicarbazide)zinc(II) dinitrate complex, $\left[\mathrm{Zn}\left(\mathrm{CH}_{5} \mathrm{~N}_{3} \mathrm{~S}\right)_{2}\right]\left(\mathrm{NO}_{3}\right)_{2}$, was studied. The Hansen-Coppens multipole model was used to extract the electron density from high resolution X-ray diffraction data collected at $100 \mathrm{~K}$. Careful strategies were designed for the electron density refinements regarding the charge transfer between the anionic and cationic parts of the complex. Particular attention was also paid to the treatment of the electron density of the zinc atom interacting with two thiosemicarbazide ligands in a tetrahedral coordination. Nevertheless, the filled $3 d$ valence shell of $\mathrm{Zn}$ was found unperturbed and only the $4 s$ shell was engaged in the metal-ligand interaction. Topological properties of both electron density and electrostatic potential, including kinetic and potential energy densities, and atomic charges were reported in order to quantify a metal-ligand complex with particular $\mathrm{Zn}-\mathrm{S}$ and $\mathrm{Zn}-\mathrm{N}$ bonds and hydrogen bonding features. Chemical activities were screened through the molecular surface on which the 3D electrostatic potential function was projected. The experimental results were confronted to those obtained from gas phase quantum calculations and a good agreement was reached between these two approaches. Finally, among other electrostatic potential critical points, the values at the maxima corresponding to the nuclear sites were used as indices of the hydrogen bonding capacity of the thiosemicarbazide ligand.

Keywords: Experimental charge density; Multipole refinement; Topological analysis; Thiosemicarbazide; Zinc complex; Hydrogen bonding 


\section{Introduction}

The metal-ligand bonding features represent an interesting area of investigation in transition metal chemistry and also in bioinorganic research. Among transition metals in biology, zinc atom is the second most abundant metal, following the iron atom. It is essential for the functionalities of a number of metalloproteins, expressing both catalytic and structural role. ${ }^{1-3}$ In biological systems, zinc ion forms complexes with proteins and nucleic acids. Zinc is very flexible considering the number of coordinated atoms which can vary from 4 to 7 , however in the case of enzymes and zinc finger proteins, the cation is usually tetrahedrally coordinated. ${ }^{1}$ Biological zinc is only present as the $d^{10} \mathrm{Zn}(\mathrm{II})$, thus most of the common spectroscopic techniques cannot provide sufficient information about the metal-ligand bonding. ${ }^{4}$

Thiosemicarbazide based compounds have been extensively studied in the last couple of decades. ${ }^{5}$ The various Schiff bases of thiosemicarbazide (the thiosemicarbazones) and their corresponding complexes have attracted much attention due to their very wide biological activities. ${ }^{6}$ Among them, complexes of $\mathrm{Zn}$ with different thiosemicarbazones, show evident antitumor activities. ${ }^{6}$ In one of the most recent studies, Cowley et al have demonstrate that $\mathrm{Zn}$ bis(thiosemicarbazone) complexes reveal the use of their intrinsic fluorescence for illumination of cancer cells, ${ }^{7}$ while Kovala-Demertzi et al have shown that some complexes of zinc with thiosemicarbazone derivatives -derivates are similar or better than cisplatin drug for their anti-proliferative activity in vitro. ${ }^{8}$

The thiosemicarbazide (TSC) itself, $\mathrm{N}^{1} \mathrm{H}_{2}-\mathrm{N}^{2} \mathrm{H}-\mathrm{C}(=\mathrm{S})-\mathrm{N}^{3} \mathrm{H}_{2}$ and its metal complexes do not show any biological activities. However, recent investigations in the field of supramolecular chemistry find some of these complexes suitable building blocks or so called "synthons" for supramolecular structures. ${ }^{9,10}$ Owing to the fact that the thiosemicarbazide is a relatively small unit, it possesses considerable hydrogen donor capacity, and therefore can be easily incorporated into hydrogen bonding 
systems. Using the $\left[\mathrm{M}(\mathrm{TSC})_{2}\right]^{2+}$ complex cations $(\mathrm{M}=\mathrm{Ni}$ and $\mathrm{Zn})$ and the anions of different dicarboxylic acids, Burrows et $a l^{9}$ have developed a synthetic method for generation of supramolecular arrays with the incorporated metal ions. ${ }^{9,10}$ In the aggregation process of these ionic spaces particular importance has been devoted to the complementary hydrogen bonding formed between pair of donors $\left(\mathrm{N}^{2}, \mathrm{~N}^{3}\right)$ of the thiosemicarbazide complex and the pair of acceptors that are the oxygen atoms of the carboxylate group. The complementary hydrogen bonding, which is assigned in the Etter's graph set notation $^{11}$ as a $\mathrm{R}(8)_{2}^{2}$ motif, has been considered as the basis of the process of the self-assembly.

In the synthesis of all $[\mathrm{Zn}(\mathrm{TSC})]^{2+}$ polymers such as $\left[\mathrm{Zn}(\mathrm{TSC})_{2}\left(\mathrm{H}_{2} \mathrm{O}\right)_{2}\right](\text { tere })^{9 \mathrm{~g}}$ $\left[\mathrm{Zn}(\mathrm{TSC})_{2}\left(\mathrm{H}_{2} \mathrm{O}\right)_{2}\right](\mathrm{fum}),{ }^{9 \mathrm{~d}}\left[\mathrm{Zn}(\mathrm{TSC})_{2}(\mathrm{citr})\right] \cdot \mathrm{H}_{2} \mathrm{O}^{9 \mathrm{~d}}$ and $\left\{\left[\mathrm{Zn}(\mathrm{TSC})\left(\mu-\mathbf{\kappa}^{1}, \mathbf{\kappa}^{2} 1,2\right.\right.\right.$-malonate $\left.)\right] \cdot \mathrm{H}_{2} \mathrm{O}_{\mathrm{n}},{ }^{9 \mathrm{a}}($ tere $=$ terephthalate, fum $=$ fumarate, citr $=$ citraconate $),$ TSC has been used to provide the cationic synthon for these aggregates. Moreover, besides the donor capacity of TSC in building up hydrogen bonded polymers, the formed M-L bonds are sufficiently strong, due to the high coordination abilities of TSC ligand. Consequently, this ligand will be not replaced with, for example, the terephthalate anion, known as a rather strong ligand ${ }^{12}$ and which in this case would only serve as a hydrogen bond acceptor (anionic synthon).

Among the different methods employed to investigate the nature of the chemical bonds and noncovalent interactions, the experimental charge density analysis ${ }^{13 a}$ has proven to be very useful since it offers the information on the electronic level. ${ }^{13}$ Due to the particular electronic configuration of the zinc atom $\left(3 d^{10} 4 s^{2}\right)$ with filled $3 d$ shell unaffected by the ligand field strength ${ }^{14}$ and energetically stable the respect to the acceptor ligand, this element is particularly interesting from the aspect of the charge density analysis. However, in the case of the zinc containing compounds (including coordination and inorganic complexes) a very few publications have been reported. ${ }^{15-17}$ To our knowledge only two of them describe the electronic properties of the zinc complex compounds. ${ }^{16,17}$

The octahedral $\left[\mathrm{Zn}\left(\mathrm{C}_{4} \mathrm{O}_{4}\right)\left(\mathrm{H}_{2} \mathrm{O}\right)_{4}\right]$ has been investigated as a part of the systematic charge density study performed to explore the bonding properties of different $3 d$ metal ions to the squarate ligand. ${ }^{16}$ 
These complexes showed consistent deformation density and topological features, however in contrast to $\mathrm{Fe}, \mathrm{Co}$ and $\mathrm{Ni}$ ions which are nearly neutral, Zn atom was found highly positively charged $(+1.97 \mathrm{e})$. The total number of $d$ electrons was also refined and was found equal to 8.4 e for the $\mathrm{Zn}$ atom. In the experimental charge density of the tetrahedral $\left[\mathrm{Zn}(\text { aspirinate })_{2}\left(\mathrm{H}_{2} \mathrm{O}\right)_{2}\right]$ a $3 d^{10}$ metal bonding to a drug ligand has been investigated. The analysis revealed that in this complex only the $\mathrm{Zn} 4 s$ orbital participates in the interaction with ligand, while the metal $3 d$ shell remains unperturbed. In this compound, the net atomic charge of $\mathrm{Zn}$ atom was found equal to $+1.29 \mathrm{e}^{17}$

In the present study, we present the results of the experimental charge density of $\left[\mathrm{Zn}(\mathrm{TSC})_{2}\right]\left(\mathrm{NO}_{3}\right)_{2}$ complex where zinc metal is tetrahedrally coordinated to the simple bidentate ligand, thiosemicarbazide, $\mathrm{N}^{1} \mathrm{H}_{2}-\mathrm{N}^{2} \mathrm{H}-\mathrm{C}(=\mathrm{S})-\mathrm{N}^{3} \mathrm{H}_{2}$, comprising $\mathrm{N}$ and $\mathrm{S}$ donor atoms. The crystal structure of $\left[\mathrm{Zn}(\mathrm{TSC})_{2}\right]\left(\mathrm{NO}_{3}\right)_{2}$ has been derived at room temperature by Ramanenko et $a l^{18 \mathrm{a}}$ and Tong $e t$ al. ${ }^{18 \mathrm{~b}}$ Considering the quality of the crystallographic data in both cases this structure could be classified as one of the best among the thiosemicarbazide based structures deposited deposed in CSD. ${ }^{19}$ Such a property makes it very suitable for an experimental charge density analysis.

High resolution and accurate experiment at low temperature $(100 \mathrm{~K})$ has been performed. This allows to carefully analyze the electron density distribution in the $\left[\mathrm{Zn}(\mathrm{TSC})_{2}\right]\left(\mathrm{NO}_{3}\right)_{2}$ complex. Through these analyses, we have gained additional insights into the nature of the M-L bond for a metal filled $d$ orbital. As far as we know, this is the first charge density study of any transition metal complex with thiosemicarbazide based ligand. However, the electron density of two TSC based ligands has already been studied: 1-formyl-3-thiosemicarbazone ${ }^{20}$ and salycyladehyde thiosemicarbazone. ${ }^{21}$

We also explore the coordination properties of the non-substituted ligand at the electronic level by $a b$ initio calculations. It should bear in mind that $\mathrm{N}^{1} \mathrm{~S}$ coordination mode and formation of five membered chelate ring represents the basic property of almost all TSC based transition metal complexes. ${ }^{5}$ Due to the presence of the nitrate group as an anion, the title compound also forms extensive hydrogen bonding network. It contains above described complementary $\mathrm{R}(8)_{2}^{2}$ hydrogen bonding motif ${ }^{11}$, which is, in this 
case, formed with the nitrate oxygen as the acceptor pair. Thus, we were prompted to explore the complex system of the hydrogen bonding interactions present in this crystal structure. Subsequent application of the topological analysis ${ }^{22}$ to the determined experimental electron density was of particular significance in revealing the nature of the chemical bonds and interactions. Finally, since the title compound is used as a reactant in supramolecular synthesis we have derived the net atomic charges and electrostatic potential within this molecule in attempt to understand its further reactivity. ${ }^{13}$

\section{Experimental section}

\section{Data collection}

A well formed colorless crystal sample of $\left[\mathrm{Zn}(\mathrm{TSC})_{2}\right]\left(\mathrm{NO}_{3}\right)_{2}$, with the dimensions $0.47 \times 0.43 \times 0.30$ $\mathrm{mm}^{3}$ was chosen for the high resolution X-ray diffraction experiment. The data were collected at 100.0(1) $\mathrm{K}$ on a Bruker-SMART three axis diffractometer equipped with a SMART 1000 CCD area detector using graphite monochromated Mo $K \alpha$ X-ray radiation (wavelength $\lambda=0.71073 \AA$ ). The low temperature was reached by an evaporated liquid nitrogen flux over the crystal, provided by the Oxford Cryosystem device. The area detector surface was placed at $4.08 \mathrm{~cm}$ from the crystal sample. The diffraction data were collected at five different detector positions: $2 \theta=0,28,-45,60,-85^{\circ}$ where $\theta$ is the Bragg angle. The diffraction data were collected as $\omega$-scans, with the scan width of $-0.15^{\circ}$. The maximum resolution reached for this experimental data set was $(\sin \theta / \lambda)_{\max }=1.10 \AA^{-1}$. The Lorentzpolarization correction and the integration of the diffracted intensities were performed with the SAINT software package. ${ }^{23}$ The final refined cell parameters are given in Table 1 . An empirical absorption correction was applied using the SADABS computer program. ${ }^{23}$ The SORTAV program ${ }^{24}$ has been used for final data sorting and averaging of 55584 reflections collected giving a total of 7616 unique reflections with final $\mathrm{R}_{\mathrm{int}}=1.7 \%$. In the conventional and multipole refinement a total of 5904 
reflections were used.

Table 1. Crystallographic details.

\begin{tabular}{|c|c|}
\hline Empirical formula & {$\left[\mathrm{Zn}\left(\mathrm{CH}_{5} \mathrm{~N}_{3} \mathrm{~S}\right)_{2}\right]\left(\mathrm{NO}_{3}\right)_{2}$} \\
\hline Formula weight $\left(\mathrm{g} \cdot \mathrm{mol}^{-1}\right)$ & 371.7 \\
\hline Crystal system & monoclinic \\
\hline Space group & $\mathrm{C} 2 / \mathrm{c}$ \\
\hline Crystal size, color & $0.47 \times 0.43 \times 0.30$, colorless \\
\hline$a(\AA)$ & $10.9541(3)$ \\
\hline$b(\AA)$ & $7.5673(2)$ \\
\hline$c(\AA)$ & $14.1753(3)$ \\
\hline$\alpha\left(^{\circ}\right)$ & 90 \\
\hline$\beta\left(\left(^{\circ}\right)\right.$ & $101.630(2)$ \\
\hline$\gamma\left({ }^{\circ}\right)$ & 90 \\
\hline $\mathrm{Z}$ & 4 \\
\hline Volume $\left(\AA^{3}\right)$ & $1150.90(6)$ \\
\hline Density $\left(\mathrm{g} \cdot \mathrm{cm}^{-3}\right)$ & 2.15 \\
\hline$\mu\left(\mathrm{mm}^{-1}\right)$ & 2.54 \\
\hline $\mathrm{T}(\mathrm{K})$ & $100.0(1)$ \\
\hline$\lambda(\AA)$ & 0.71073 \\
\hline$(\sin \theta / \lambda)_{\max }\left(\AA^{-1}\right)$ & 1.10 \\
\hline No. of data collected & 55584 \\
\hline No. of unique reflns & 7616 \\
\hline $\mathrm{R}_{\text {int }}(\%)$ & 1.67 \\
\hline Conventional refinement by SHELX & \\
\hline No. of reflns used & 6178 \\
\hline $\mathrm{R}(\%)$ & 1.90 \\
\hline
\end{tabular}




\begin{tabular}{|l|l|}
\hline $\mathrm{Rw}(\%)$ & 4.40 \\
Gof & 1.03 \\
Multipole refinement & \\
No. reflns used (I>3\%(I)) & 5904 \\
$\mathrm{R}[\mathrm{F}](\%)$ & 1.15 \\
$\mathrm{Rw}[\mathrm{F}](\%)$ & 1.33 \\
$\mathrm{Gof}$ & 0.88 \\
\hline
\end{tabular}

\section{Electron density distribution}

The Hansen-Coppens multipole model has been used for the description of the molecular electron density. ${ }^{25}$

$$
\rho_{\text {at }(\mathrm{r})}=\rho_{\text {core }(\mathrm{r})}+P_{\mathrm{val}} \kappa^{3} \rho_{\mathrm{val}}(\kappa \mathrm{r})+\kappa^{\prime 3} \sum_{\mathrm{l}=0}^{l_{\max }} R_{\mathrm{nl}}\left(\kappa^{\prime} \mathrm{r}\right) \sum_{\mathrm{m}=0}^{1} \mathrm{P}_{\mathrm{lm} \pm} \mathrm{y}_{\mathrm{lm} \pm}(\theta, \varphi)
$$

According to this model, the electron density of each atom is given as a sum of a core electron density $\left(\varrho_{\text {core }}\right)$, a spherical valence electron density $\left(\varrho_{\text {valence }}\right)$ and aspherical part of the atomic electron density. The core and valence electron densities are both obtained from the Hartree-Fock wave function of the free atoms or ions. $x$ is a contraction-expansion coefficient which modifies the radial distribution of the valence electron density. It is refined along with the $\mathrm{P}_{\text {val }}$ parameter which represents valence electron population. The atomic charge thus can be estimated as: $q=P_{v a l}-N_{v a l}$ where $N_{v a l}$ is the population of the free atom. The final term which describes the aspherical part of the electron density is given as a series of density normalized spherical harmonics. The radial part for the deformation function is given as Slater type function: $R_{n 1}(r)=N r^{n}{ }_{l} \exp \left(-\xi_{l} r\right)$, where $\mathrm{N}$ is a normalization factor. In equation (1) the $x^{\prime}$ is the contraction-expansion coefficient of the radial part of aspherical valence shell, while $\mathrm{P}_{l m}$ are multipole population parameters. The $\xi_{l}$ exponents $\left(\right.$ in bohr $^{-1}$ ) are chosen equal to 3.0 and 4.5 and $n_{l}=2$, 
2, 3 up to octupoles $\left(1=3\right.$ ) for $\mathrm{C}$ and $\mathrm{O}$ atoms respectively; $\xi_{l}=2.26 \mathrm{bohr}^{-1}$ and $n_{l}=1$ (dipole level, $l=$

1) for the hydrogen atoms; $\xi_{l}=4.1 \mathrm{bohr}^{-1}$ and $n_{l}=4,4,4,6$ up to hexadecapole $(1=4)$ for S. Taking into account the special position of the metal ion, the local coordinate system for the $\mathrm{Zn}$ atom was defined in such a way that the principal axis was parallel to the 2 -fold axis (the local axis divides the interligand angle $\mathrm{S} 1-\mathrm{Zn}-\mathrm{S} 1$ ' i.e. it is directed toward the dummy atom placed in the middle point of the $\mathrm{S} 1 \ldots \mathrm{S} 1$ ' line). Assuming that the $3 d$ shell electron density of a transition metal like $\mathrm{Zn}\left(3 d^{10} 4 s^{2}\right)$ is fully described by the even orders $l=0,2,4$ of the multipolar expansion (equation 1 ), one monopole $\left(\mathrm{P}_{00}\right)$, the quadrupoles, and hexadecapoles can be introduced for the zinc. For all refinements in this study, the $\mathrm{P}_{\text {val }}$ population was always assigned to the diffuse $4 s$ electron density of the zinc metal atom.

\section{Refinement strategies}

The crystal structure was determined on the basis of accurate low temperature data using the WinGX program packing. ${ }^{26}$ Conventional and electron density refinements were performed with the MOLLY program implementing Hansen-Coppens multipole model. ${ }^{25}$ In the first cycles of the refinements, to obtain the best estimation of the atomic positional and thermal parameters for non- $\mathrm{H}$ atoms the high $\operatorname{order}\left(\sin \theta / \lambda>0.8 \AA^{-1}\right)$ refinement strategy was first applied. Residual Fourier maps calculated with high order data revealed features of the anharmonic thermal motion for Zn, thus Gramm-Charlier expansion $^{27}$ up to sixth order was included for $\mathrm{Zn}$ atom during the refinement. Before the electron density refinement the positions of hydrogen atoms were extended to the corresponding neutron distances $^{28}$. The $\mathrm{N}-\mathrm{H}$ bond lengths are relaxed in the last cycle of refinement.

Two strategies have been applied during the multipole refinement. In the first case the neutrality constraint was imposed to the complex as a whole allowing for charge transfer between the ionic spaces (strategy I). This refinement started by considering a neutral zinc atom with separated $3 d$ and $4 s$ valence shells. In the second refinement the charges within the ions are constrained to +2 for cation and -1 for 
each anion, not allowing a charge transfer between the ions (strategy II). In the start of the refinement by the strategy II, the positive charge of +2 was located on $\mathrm{Zn}$ atom $\left(\mathrm{P}_{\mathrm{val}}=0\right)$, while the excess of negative charge of 1 e was split between the oxygen atoms of $\mathrm{NO}_{3}$ anion. All attempts to refine the $\mathrm{Zn}$ multipole parameters failed and have yielded unrealistic $3 d$ occupations larger than 2 electrons per orbital. However with fixed $\mathrm{P}_{00}(3 d)$ it was possible to refine $\mathrm{Zn}$ multipole parameters and these results are presented in the second part of the Supporting Information. The second monopole $\mathrm{P}_{00}(3 d)$ refined value remained stable at 10 e and was fixed in the subsequent refinements whereas multipole parameters were set to zero. Consequently, in final strategies (I and II) the second monopole $\mathrm{P}_{00}(3 d)$ value was fixed at 10 e whereas multipole parameters were set to zero, that is, only the $\mathrm{Zn} 4 s$ orbital interaction with the ligands has been finally considered in this study. A similar refinement method was successfully applied in the case of tetrahedral $\left[\mathrm{Zn}(\text { aspirinate })_{2}\left(\mathrm{H}_{2} \mathrm{O}\right)_{2}\right]{ }^{17}$

The main differences between the results obtained by these two strategies consist in the values of the atomic charges which are calculated after a $\varkappa$-refinement. Namely, in contrast to strategy II where the charges of ions are fixed $\left(\left[\mathrm{Zn}(\mathrm{TSC})_{2}\right]^{+2}\right.$ and $\left.2\left(\mathrm{NO}_{3}\right)^{-1}\right)$, unconstrained strategy $\mathbf{I}$ led to the values of $+1.92(28)$ e and $-0.95(10)$ e for the cation and each of the anions respectively. The statistical least square features did not differ significantly between these two strategies thus the results presented in this work correspond to those obtained by the strategy $\mathbf{I}$. The detailed results for both strategies are included in Supporting Information. The crystallographic details are presented in Table 1. Figure 1 represents the residual density map obtained after the multipole refinement for the plane of the complex cation and the $\mathrm{NO}_{3}$ anion. The residual electron densities are computed as Fourier transform of the $\left(\mathrm{F}_{\mathrm{o}}-\mathrm{F}_{\mathrm{c}}\right)$ difference where $F_{o}$ and $F_{c}$ were observed and model calculated structure factors. The residual density maps are essentially featureless. The highest residual density peaks of 0.2 e $\AA^{-3}$ are found in the vicinity of the $\mathrm{Zn}$ atom. 


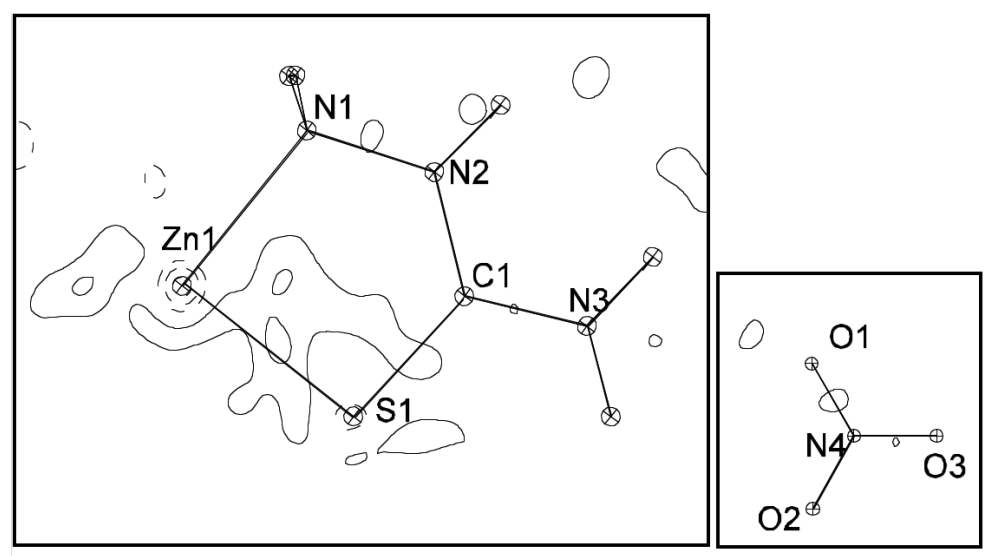

Figure 1. Residual electron density maps: (a) Zn1-C1-N1 plane; (b) N4-O3-O1 plane. The contour interval is $0.1 \mathrm{e} \cdot \AA^{-3}$; negative contours are dashed, zero contour omitted.

\section{Computational method}

Theoretical calculations have been performed with DFT calculation methods using the Gaussian 03 program package. ${ }^{29}$ In the case of the title compound, $\left[\mathrm{Zn}(\mathrm{TSC})_{2}\right]\left(\mathrm{NO}_{3}\right)_{2}$ and its TSC ligand (which in complex molecule displays cis-configuration) the coordinates used in calculations are those obtained from the multipole refinement. The coordinates of the analyzed $\mathrm{Zn}$ supramolecular complexes ${ }^{9 \mathrm{~g}, 9 \mathrm{~d}}$ have been extracted from CSD bank (Table 2). The coordinates of the to additional forms of the TSC ligand, the trans-TSC ${ }^{30}$ and the protonated $c i s-\mathrm{TSC}^{31}$ have been also extracted from CSD bank For all extracted compounds the corresponding N-H bond lengths are elongated to the experimental values obtained after the multipole refinement of the title compound. The optimizations of the molecules were not performed. The calculation of the electrostatic potential and electrostatic potential at the nuclear sites have been performed in a vacuum using B3LYP functional with $6-31++G(2 d, 2 p)$ basis set as suggested by Dudev and Lim for the $\mathrm{Zn}$ containing compounds. ${ }^{3}$

Table 2 Labelling of the compounds used in this paper

\begin{tabular}{|l|l|l|}
\hline Compound & reference & CSD code \\
\hline $\mathrm{N}^{1} \mathrm{H}_{2}-\mathrm{N}^{2} \mathrm{H}-\mathrm{C}(=\mathrm{S}) \mathrm{N}^{3} \mathrm{H}_{2}$ TSC & 30 & TSCRBZ20 \\
\hline
\end{tabular}




\begin{tabular}{|l|l|l|}
\hline$\left[\mathrm{Zn}(\mathrm{TSC})_{2}\left(\mathrm{H}_{2} \mathrm{O}\right)_{2}\right]($ tere $)$ & $9 \mathrm{~g}$ & PABQEO \\
{$\left[\mathrm{Zn}(\mathrm{TSC})_{2}\left(\mathrm{H}_{2} \mathrm{O}\right)_{2}\right]($ fum $)$} & $9 \mathrm{~d}$ & RUZPIL \\
{$\left[\mathrm{Zn}(\mathrm{TSC})_{2}(\mathrm{citr})\right] \cdot \mathrm{H}_{2} \mathrm{O}$} & $9 \mathrm{~d}$ & RUZPOR \\
{$\left[\left\{\left[\mathrm{Zn}(\mathrm{TSC})\left(\mu-\kappa^{1}, \mathrm{~K}^{2} 1,2 \text {-malonate }\right)\right] \cdot \mathrm{H}_{2} \mathrm{O}\right\}_{\mathrm{n}}\right.$} & $9 \mathrm{a}$ & QARTOT \\
{$\left[\mathrm{Zn}\left(\mathrm{C}_{4} \mathrm{O}_{4}\right)\left(\mathrm{H}_{2} \mathrm{O}\right)_{4}\right]$} & 16 & - \\
{$\left[\mathrm{Zn}(\text { aspirinate })_{2}\left(\mathrm{H}_{2} \mathrm{O}\right)_{2}\right]$} & 17 & DASFUY \\
{$\left[\mathrm{Zn}(\mathrm{TSC})_{2}\right]\left(\mathrm{NO}_{3}\right)_{2}$} & $18 \mathrm{a}, \mathrm{b}$ this work & TSEMHC \\
$\mathrm{N}^{1} \mathrm{H}_{2}-\mathrm{N}^{2} \mathrm{H}_{-} \mathrm{C}(=\mathrm{S}) \mathrm{N}^{3} \mathrm{H}_{3} \mathrm{TSCH}^{+}$ & 31 & \\
{$\left[\mathrm{Zn}(\mathrm{TSC})_{2}\right]^{2+}$} & & \\
{$\left[\mathrm{Zn}(\mathrm{TSC})_{2}\left(\mathrm{H}_{2} \mathrm{O}\right)_{2}\right]^{2+}$} & & \\
\hline
\end{tabular}

\section{Results and discussion}

\section{Crystal structure}

The crystal structure of the title compound consists of $\left[\mathrm{Zn}(\mathrm{TSC})_{2}\right]^{+2}$ complex cations and nitrate anions. $\mathrm{Zn}$ atom is located in a tetrahedral environment formed by two bidentate thiosemicarbazide ligands comprising $\mathrm{N}$ and $\mathrm{S}$ donor atoms. Figure 2 depicts the ORTEP view of the crystal structure. Inspection of the geometrical parameters does not reveal significant difference from the room temperature data. ${ }^{18}$ Due to the small bite angle of TSC ligand $\left(88.47(6)^{\circ}\right)$, the tetrahedral coordination geometry $\left(109.28^{\circ}\right)$ of the complex is significantly deformed. The intermediary values of two N-C and $\mathrm{C}=\mathrm{S}$ bond lengths (column 2 in Table 3) suggest a considerable degree of delocalization within the ligand. Consequently, the chelate ring is practically planar with the mean plane deviation of the constitute atoms of $0.014 \AA$. 


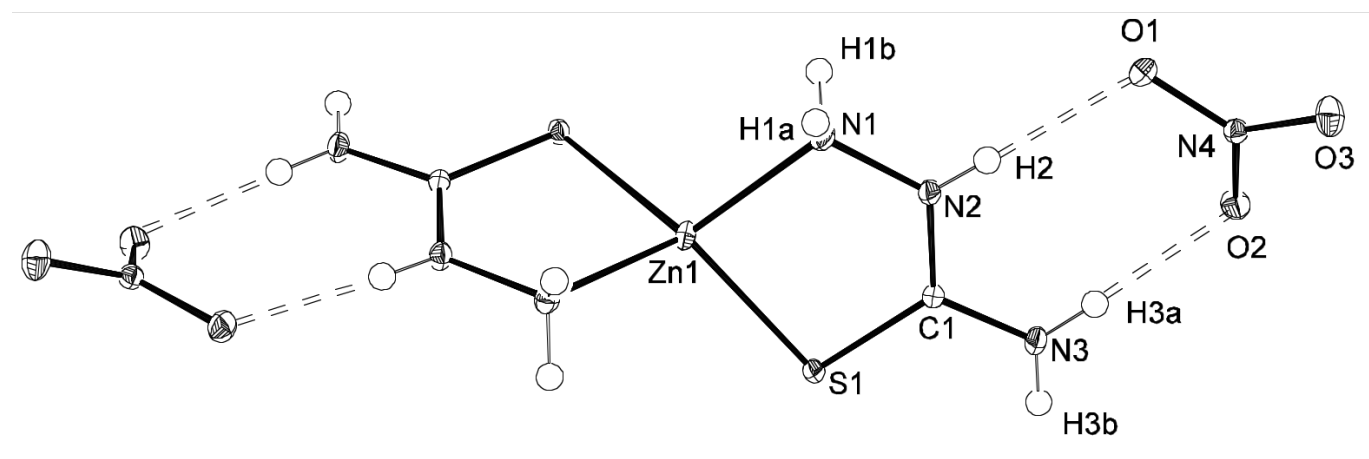

Figure 2. Crystal structure of $\left[\mathrm{Zn}(\mathrm{TSC})_{2}\right]\left(\mathrm{NO}_{3}\right)_{2}$.

Due to the high hydrogen donating capacity of the complex cation and the presence of the $\mathrm{NO}_{3}$ anion as an acceptor, crystal packing of $\left[\mathrm{Zn}(\mathrm{TSC})_{2}\right]\left(\mathrm{NO}_{3}\right)_{2}$ exhibits a rather complex hydrogen bonding network. There are nine hydrogen bonds of the same N-H...O type involved in stabilization of the complex. It is important to mention that two of the five hydrogen atoms existing in this structure are involved in a bifurcated and one in a trifurcated hydrogen bond which additionally increasing the complexity of the pattern (Table 4$)$.

Table 3. Interatomic distances and topological properties of the electron density for the covalent bonds. $\mathrm{d} 1, \mathrm{~d} 2$ are the distances $(\AA)$ from the critical point to atoms 1 and 2 respectively; $\mathrm{Q}\left(\mathrm{r}_{\mathrm{cp}}\right)$ is the electron density in $\left(\mathrm{e} \cdot \AA^{-3}\right) ; \nabla^{2} \mathrm{Q}\left(\mathrm{r}_{\mathrm{cp}}\right)$ is the Laplacian (in $\left.\mathrm{e} \cdot \AA^{-5}\right), \lambda_{1}, \lambda_{2}, \lambda_{3}$ are the principle curvatures in $\left(\mathrm{e} \cdot \AA^{-5}\right)$, is the ellipticity, $G, V, H$ are kinetic energy density, potential energy density and total energy density respectively in $\left(\mathrm{KJ} \cdot \mathrm{mol} \cdot \mathrm{bohr}{ }^{-3}\right)$.

\begin{tabular}{|l|c|c|c|c|c|c|c|c|c|c|c|c|}
\hline \multicolumn{1}{|c|}{ Bond } & Length & $\mathrm{d}_{1}$ & $\mathrm{~d}_{2}$ & $\varrho\left(\mathrm{r}_{\mathrm{cp}}\right)$ & $\nabla^{2} \mathrm{\varrho}\left(\mathrm{r}_{\mathrm{cp}}\right)$ & $\lambda_{1}$ & $\lambda_{2}$ & $\lambda_{3}$ & $\varepsilon$ & $G\left(\mathrm{r}_{\mathrm{cp}}\right)$ & $V\left(\mathrm{r}_{\mathrm{cp}}\right)$ & $H\left(\mathrm{r}_{\mathrm{cp}}\right)$ \\
\hline $\mathrm{Zn} 1-\mathrm{N} 1$ & $2.0918(2)$ & 0.999 & 1.093 & 0.52 & 7.16 & -2.89 & -2.70 & 12.76 & 0.07 & 234.80 & -274.91 & -40.11 \\
$\mathrm{Zn} 1-\mathrm{S} 1$ & $2.2667(2)$ & 1.047 & 1.221 & 0.41 & 5.20 & -1.81 & -1.68 & 8.55 & 0.08 & 162.44 & -187.22 & -24.78 \\
$\mathrm{~N} 1-\mathrm{N} 2$ & $1.4114(2)$ & 0.716 & 0.696 & 2.06 & -3.56 & -16.17 & -15.10 & 27.71 & 0.06 & 1059.91 & -2207.65 & -1147.74 \\
$\mathrm{C} 1-\mathrm{N} 2$ & $1.3419(3)$ & 0.554 & 0.788 & 2.35 & -22.32 & -19.26 & -16.72 & 13.66 & 0.15 & 883.40 & -2373.71 & -1490.31 \\
$\mathrm{C} 1-\mathrm{N} 3$ & $1.3274(3)$ & 0.554 & 0.773 & 2.43 & -23.20 & -20.58 & -16.58 & 13.95 & 0.21 & 941.66 & -2514.18 & -1572.5 \\
$\mathrm{C} 1-\mathrm{S} 1$ & $1.7194(2)$ & 0.911 & 0.809 & 1.30 & -2.61 & -7.00 & -5.66 & 10.04 & 0.24 & 436.25 & -934.47 & -507.22 \\
$\mathrm{O} 1-\mathrm{N} 4$ & $1.2561(2)$ & 0.624 & 0.632 & 3.07 & -5.83 & -26.43 & -23.47 & 44.08 & 0.13 & 1919.45 & -3997.43 & -2077.98 \\
O2-N4 & $1.2568(3)$ & 0.622 & 0.635 & 3.08 & -6.03 & -26.65 & -23.62 & 44.24 & 0.13 & 1926.85 & -4017.65 & -2090.80 \\
\hline
\end{tabular}




\begin{tabular}{|l|c|c|c|c|c|c|c|c|c|c|c|c|}
\hline O3-N4 & $1.2418(3)$ & 0.622 & 0.619 & 3.20 & -10.82 & -28.30 & -24.11 & 41.58 & 0.17 & 1973.74 & -4241.99 & -2268.25 \\
N1-H1a & $0.997(10)$ & 0.728 & 0.296 & 2.16 & -19.49 & -28.59 & -26.34 & 33.44 & 0.09 & 773.84 & -2077.56 & -1303.72 \\
N1-H1b & $1.030(9)$ & 0.735 & 0.295 & 2.06 & -16.70 & -24.99 & -23.12 & 31.43 & 0.08 & 738.79 & -1931.69 & -1192.90 \\
N2-H2 & $0.991(10)$ & 0.740 & 0.250 & 2.12 & -21.76 & -29.04 & -26.62 & 33.91 & 0.09 & 698.12 & -1986.92 & -1288.80 \\
N3-H3a & $1.006(10)$ & 0.756 & 0.250 & 2.14 & -27.40 & -29.18 & -27.31 & 29.90 & 0.07 & 613.10 & -1971.24 & -1358.14 \\
N3-H3b & $0.984(10)$ & 0.722 & 0.262 & 2.27 & -24.96 & -31.35 & -29.07 & 35.46 & 0.08 & 771.98 & -2222.65 & -1450.67 \\
\hline
\end{tabular}

As previously mentioned the complex cation provides a combination of the hydrogen bonding donors suitably oriented for the interaction with the anion hydrogen bonding acceptor pair. Thus, the complementary hydrogen bonds are formed on each side of the molecule involving hydrazine (N2-H2) and thioamide (N3-H3a) fragments on the ligand side and $\mathrm{O} 1, \mathrm{O} 2$ acceptor pair of the $\mathrm{NO}_{3}$ anion. The hydrogen bonding motif formed in this way (Figure 2) can be assigned in Etter's graph set notation as $\mathrm{R}(8)_{2}^{2} .{ }^{11}$ According to geometrical parameters presented in Table 4, these complementary hydrogen bonds exhibit the shortest length and very good directionality (with quite large N-H...O angles). In these interactions donor and acceptor atoms are forming a torsion angle, N2-N3-O1-O2, of $8.2^{\circ}$. However the dihedral angle formed between the mean planes of the chelate ring and the nitrate anion is $31.1^{\circ}$. It seems that the engagement of the third oxygen atom of the $\mathrm{NO}_{3}$ anion in the additional relatively strong N1-H1a...O3 hydrogen bond slightly shifts the acceptor plane. This third hydrogen bond connects the neutral complex molecules into an extended ribbon as presented in Figure 3a. Due to the presence of the second row axis passing through the metal ion and changing the orientation of the donors, the ribbon takes a more twisted form. The ribbons are further mutually interconnected by two medium, N3-H3b...O1 and N1-H1b...O3 and four weaker hydrogen bonds (minor components ${ }^{32}$ ), giving rise to more complex hydrogen bonded arrangements. Part of the crystal packing is shown on Figure 3(b). 


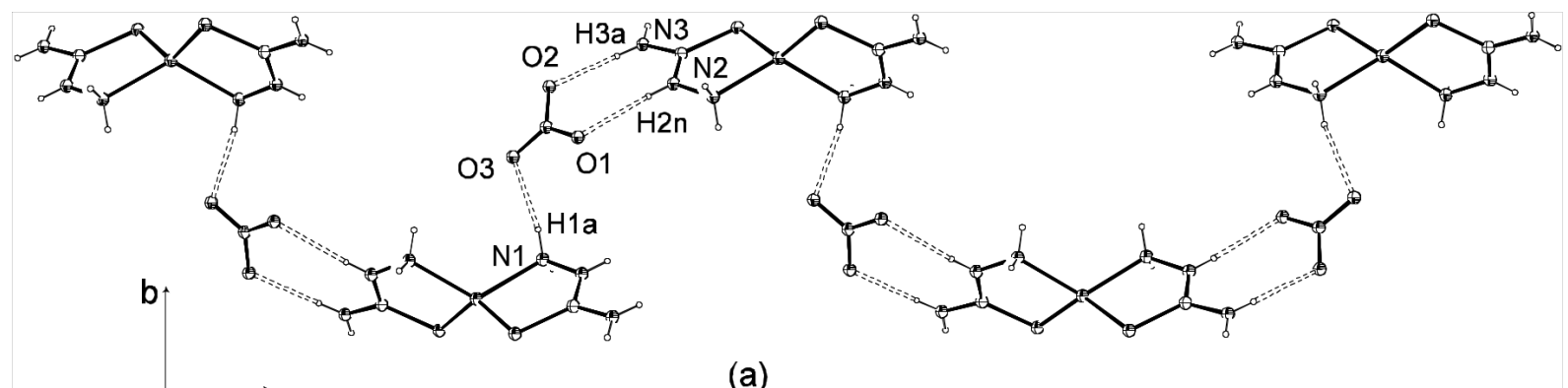

(a)

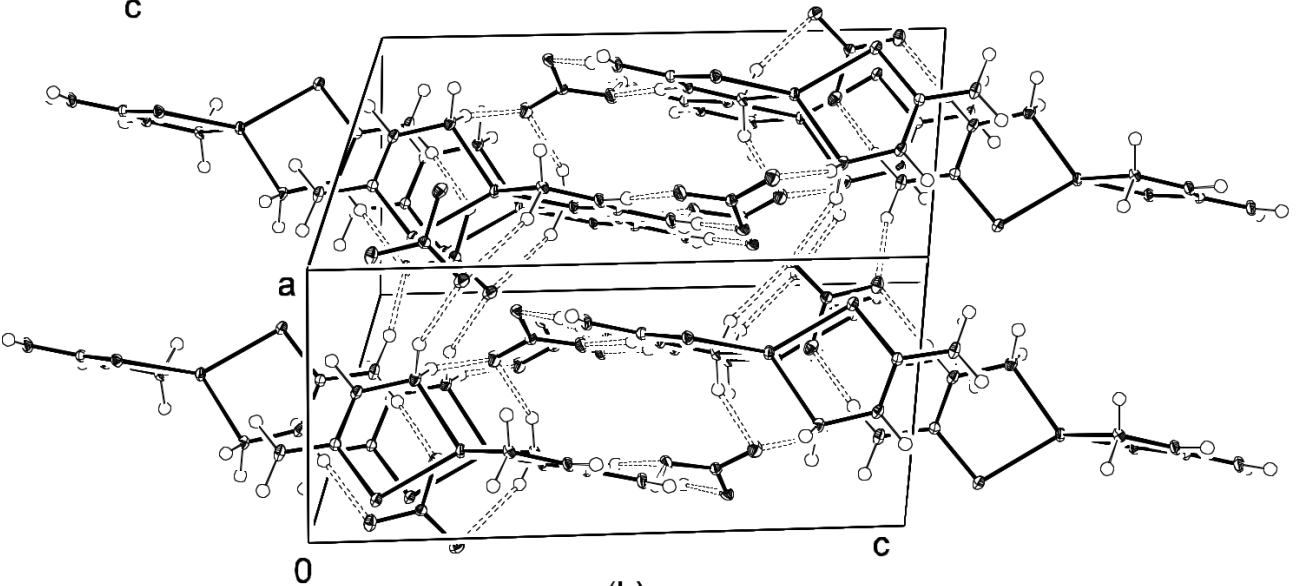

(b)

Figure 3. (a) One dimensional chain formed by the strongest hydrogen bonds; (b) segment of the crystal packing of $\left[\mathrm{Zn}(\mathrm{TSC})_{2}\right]\left(\mathrm{NO}_{3}\right)_{2}$.

Table 4. Interatomic distances and topological properties of the electron density for the hydrogen bonds. Properties and unites defined in Table 13.

\begin{tabular}{|c|c|c|c|c|c|c|c|c|c|c|c|c|c|c|}
\hline Bond & $\begin{array}{c}\text { N...O } \\
(\AA)\end{array}$ & $\begin{array}{l}\text { H...O } \\
(\AA)\end{array}$ & $\begin{array}{c}\mathrm{N}-\mathrm{H} \ldots \mathrm{O} \\
\left({ }^{\circ}\right)\end{array}$ & d1 & d2 & $\rho\left(r_{c p}\right)$ & $\nabla^{2} \mathrm{Q}\left(\mathrm{r}_{\mathrm{cp}}\right)$ & $\lambda_{1}$ & $\lambda_{2}$ & $\lambda_{3}$ & $\varepsilon$ & $G\left(\mathrm{r}_{\mathrm{cp}}\right)$ & $V\left(\mathrm{r}_{\mathrm{cp}}\right)$ & $H\left(\mathrm{r}_{\mathrm{cp}}\right)$ \\
\hline N3-H3a...O $2^{i}$ & $2.8502(4)$ & $1.8456(3)$ & 175.51(2) & 0.622 & 1.228 & 0.10 & 4.07 & -0.55 & -0.52 & 5.14 & 0.08 & 80.50 & -50.33 & 30.17 \\
\hline $\mathrm{N} 2-\mathrm{H} 2 \ldots \mathrm{O} 1^{\mathrm{i}}$ & 2.9141(3) & $1.9239(3)$ & $178.46(3)$ & 0.695 & 1.229 & 0.13 & 2.97 & -0.69 & -0.68 & 4.32 & 0.03 & 64.25 & -47.77 & 16.48 \\
\hline $\mathrm{N} 1-\mathrm{H} 1 \mathrm{a} \ldots . . \mathrm{O} 3^{\mathrm{ii}}$ & $2.9272(4)$ & $1.9906(3)$ & $155.56(2)$ & 0.723 & 1.286 & 0.08 & 2.63 & -0.47 & -0.39 & 3.47 & 0.19 & 52.77 & -34.84 & 17.93 \\
\hline $\mathrm{N} 3-\mathrm{H} 3 \mathrm{~b} \ldots \mathrm{O} 1^{\mathrm{iii}}$ & $3.00804)$ & $1.9954(2)$ & $156.12(2)$ & 0.800 & 1.371 & 0.05 & 1.82 & -0.26 & -0.20 & 2.28 & 0.25 & 35.10 & -20.71 & 14.39 \\
\hline $\mathrm{N} 1-\mathrm{H} 1 \mathrm{~b} \ldots \mathrm{O} 3^{\mathrm{iv}}$ & $3.2770(5)$ & $2.2942(4)$ & $159.18(2)$ & 0.907 & 1.479 & 0.04 & 1.13 & -0.12 & -0.05 & 1.31 & 0.87 & 21.21 & -11.97 & 9.24 \\
\hline $\mathrm{N} 1-\mathrm{H} 1 \mathrm{~b} \ldots \mathrm{O} 2^{\mathrm{iv}}$ & $3.0294(4)$ & $2.4650(3)$ & $108.32(2)$ & 1.078 & 1.433 & 0.05 & 0.94 & -0.09 & -0.15 & 1.40 & 0.57 & 20.06 & -13.21 & 6.85 \\
\hline N1-H1a...O $1^{\mathrm{ii}}$ & $3.4414(4)$ & $2.5542(3)$ & $148.17(1)$ & 1.048 & 1.621 & 0.02 & 0.59 & -0.06 & -0.03 & 0.68 & 0.51 & 11.16 & -6.28 & 4.88 \\
\hline N3-H3a...O3 ${ }^{v}$ & $3.0272(4)$ & $2.5737(3)$ & $107.18(2)$ & 1.161 & 1.471 & 0.04 & 0.80 & -0.14 & -0.13 & 1.08 & 0.11 & 15.96 & -10.16 & 5.80 \\
\hline $\mathrm{N} 1-\mathrm{H} 1 \mathrm{~b} \ldots \mathrm{O} 2^{\mathrm{vi}}$ & $3.0933(4)$ & $2.6111(3)$ & $108.32(1)$ & 1.211 & 1.501 & 0.04 & 0.70 & -0.13 & -0.07 & 0.91 & 0.71 & 14.15 & -9.27 & 4.88 \\
\hline
\end{tabular}

Symmetry codes: (i) $\mathrm{x}, \mathrm{y}, \mathrm{z}$; (ii) $-\mathrm{x}+0.5,-\mathrm{y}-0.5,-\mathrm{z}+1$; (iii) $\mathrm{x}+0.5, \mathrm{y}+0.5, \mathrm{z}$; (iv) $\mathrm{x}, \mathrm{y}, \mathrm{z}+0.5$; (v) $-\mathrm{x}+0.5, \mathrm{y}+0.5,-\mathrm{z}+0.5$; (vi) $-\mathrm{x}+0.5, \mathrm{y}-0.5,-\mathrm{z}+1$. 


\section{Electron deformation density and topological properties in the complex entity}

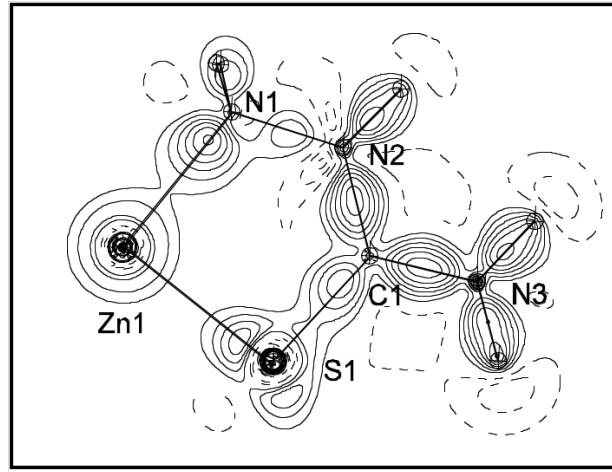

(a)

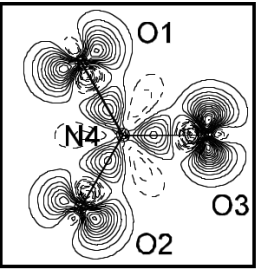

(b)

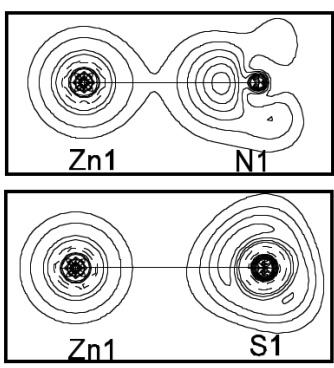

(c)

Figure 4. Static electron deformation density maps (a) Zn1-C1-N1 plane; (b) N4-O3-O1 plane; (c) in the plane orthogonal to the chelate ring. Contours are as in Figure 1.

The static electron deformation density maps ${ }^{33}$ for the plane of chelate ring of the complex cation and the nitrate anion are given in Figure 4. Within the planar thiosemicarbazide ligand, the two $\mathrm{C}-\mathrm{N}$ bonds exhibit the highest bonding densities of the similar values, 0.60 and $0.65 \mathrm{e} \cdot \AA^{-3}$. The highest density peak is found in the terminal C1-N3 bond what is in accordance with its shorter length. The densities are well centered on the bonds and do not show significant polarization. The electron deformation density in the N1-N2 bond of $0.25 \mathrm{e} \cdot \AA^{-3}$ has the lowest value found in the molecule while the $\mathrm{C}=\mathrm{S}$ bond, as a part of the conjugated system, exhibits much higher electron density peak $\left(0.45 \mathrm{e} \cdot \AA^{-3}\right)$.

For a more quantitative characterization of the bonds, a topological analysis of the total electron density has been carried out. ${ }^{22,34}$ The obtained results are listed in Table 3. According to topological features, the differences between the two $\mathrm{C}-\mathrm{N}$ bonds are more pronounced. The value of the electron density at the bond critical point (BCP) for the terminal C1-N3 bond is higher comparing to the C1-N2 bond. The higher value of the ellipticity $\varepsilon$ and the resulting local total energy densities ${ }^{35}$ for the C1-N3 bond, indicate slightly higher covalency character for this bond which is not included in the chelate ring. The position of the BCP clearly indicates that both $\mathrm{C}-\mathrm{N}$ bonds are polarized and, in both cases, the BCP 
is found at equal distance from the $\mathrm{C}$ atoms $(0.554 \AA$ ). In a recently reported charge density analysis of the uncoordinated TSC derivate 1-formyl-3-thiosemicarbazide, ${ }^{20}$ very similar topological properties have been reported for the two corresponding $\mathrm{C}-\mathrm{N}$ bonds. The values of $\mathrm{Q}$ found in the BCP of this ligand are 2.31 and $2.44 \mathrm{e} \cdot \AA^{-3}$ which is almost identical to those found in the present complex.

The values of $\varrho$ and Laplacian at the $\mathrm{BCP}$ of the $\mathrm{C}=\mathrm{S}$ bond are as expected much less than for $\mathrm{C}=\mathrm{N}$ bonds. However, the ellipticity value indicates a significant double bond character which confirms that $\mathrm{C}=\mathrm{S}$ bond is involved in the conjugation process. This is in agreement with the reported $\mathrm{C}=\mathrm{S}$ bond lengths which is of intermediary value. The lower value of ellipticity for N1-N2 bond indicates that this bond is more cylindrical and closer in nature to the single one. The reported topological features emphasize the conjugation effect which is particularly present in the thioureide fragment of the ligand. Figure 5 contains the behavior of the topological parameters $\varrho$ and $H$, obtained from the experiment, as a function of the interatomic distance for the unusual bonds (C-S, N-N, M-N, M is a transition metal) of the studied compound. The general trend for the C-S bond ${ }^{20,21,36}$ is a significant decreasing of $\varrho$ with $\mathrm{d}$ values and a relatively less increasing of the $H$ values. The values for the $\mathrm{N}-\mathrm{N}$ bonds ${ }^{37}$ are closer due to the smaller range of the $\mathrm{d}_{\mathrm{N}-\mathrm{N}}$ values. 

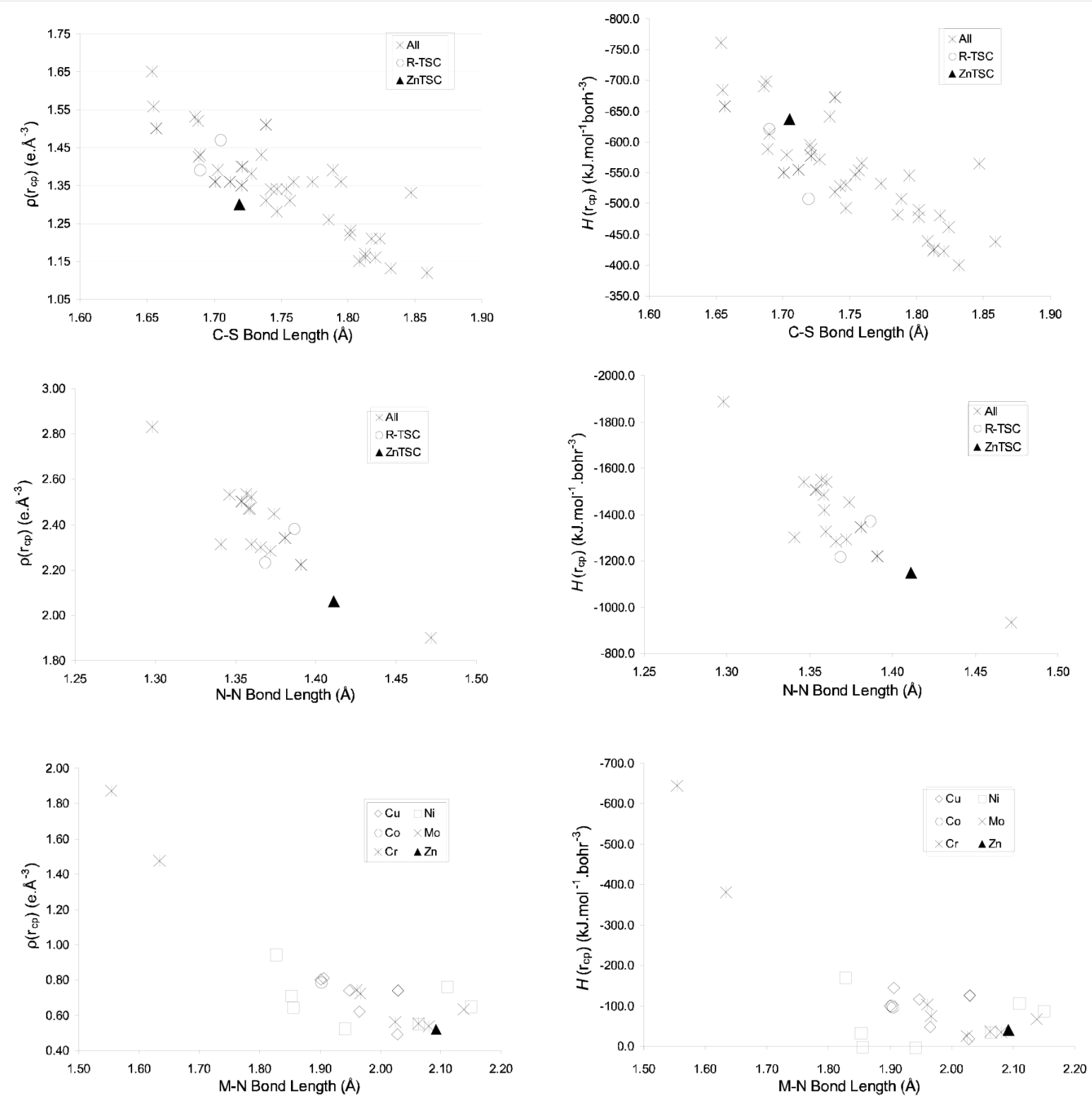

(a)

(b)

Figure 5. $\mathrm{Q}\left(\mathrm{r}_{\mathrm{c}}\right)$ vs bond length (a) and $\mathrm{H}\left(\mathrm{r}_{\mathrm{c}}\right)$ vs bond length (b) for C-S, N-N and M-N bonds. ${ }^{36-38}$ (RTSC is for other TSC based compounds ${ }^{20,21}$ ).

According to the electron deformation density maps in the plane of the chelate ring (Figure 4(a)), both $\mathrm{N}$ and $\mathrm{S}$ donor atoms exhibit electron density directed toward the $\mathrm{Zn}$ atom. The deformation density of the nitrogen atom is spared along the $\mathrm{Zn1-N1}$ bond, while in the case of sulfur the lone pair is clearly pointed toward the metal center the corresponding bonding densities are 0.60 and $0.40 \mathrm{e} \cdot \AA^{-3}$, respectively. Figure 4(c) presents the electron deformation density of the same bonds in planes 
perpendicular to the chelate ring. In both cases, the density is concentrated in the plane of the ligand (it is not splitted above and below the bond) demonstrating the $\sigma$ donor character of the ligand. Analysis of the $\mathrm{Zn1-S1} \mathrm{coordination} \mathrm{bond} \mathrm{shows} \mathrm{that} \mathrm{the} \mathrm{torus} \mathrm{shaped} \mathrm{free} \mathrm{electron} \mathrm{density} \mathrm{of} \mathrm{sulfur} \mathrm{donor} \mathrm{is} \mathrm{rather}$ described as polarized than clearly directed toward the metal ion.

In the topological analysis, the $\mathrm{Zn}-\mathrm{L}$ bonds are both characterized by positive values of Laplacian, which is typical for coordination bonds to transition metals. As expected, the $\mathrm{Zn}-\mathrm{N}$ interaction possesses larger value of $\mathrm{Q}$ at the BCP. The bond paths of coordination bonds fall almost exactly on the internuclear axis. The relatively low ellipticities found for these bonds are in accordance with their $\sigma$ character. The behavior of $\mathrm{Q}$ for the $\mathrm{M}-\mathrm{N}$ reported values (Figure 5) is in agreement with the interatomic distances, despite the fact that different bond types are compared in the same graph. The relatively very low $H$ values give an indication of the weak strength character of these bonds. In coordination bonds, the magnitude of the potential energy density slightly overcomes the value of the kinetic energy density ${ }^{35}$ ( $|V| / G$ is equal to 1.15 for $\mathrm{Zn}-\mathrm{S}$ and 1.17 for $\mathrm{Zn}-\mathrm{N}$ ) suggesting that these bonds are best described as polar covalent leading to one of the smallest ratio when compared with the literature for $\mathrm{M}-\mathrm{N}$ bond ( 3 values are in the range $0.92-0.98$, while 20 values are in the range $1.07-$ 1.7). ${ }^{37 c, 38}$ The same trend is observed for the M-S bond, but only two experiments have been reported concerning a $\mathrm{Ni}$ and a Co complex. ${ }^{36 \mathrm{e}}$

\section{Electron deformation density and topology of hydrogen bonds}

The space distribution of all the hydrogen donor groups around nitrate acceptor is illustrated in Figure 6. Figure 7(a) displays the static electron deformation density maps (in N-H...O planes) corresponding to the first three strongest hydrogen bonds, while Figure 7(b) displays the polarization of each oxygen's lone pair in a plane containing the oxygen atom and the two hydrogen atoms which form the strongest hydrogen bonds. When the oxygen lone pair is involved in the slightly equivalent hydrogen bonds (case 
of O1) the electron density of the free electron pairs is equitably oriented toward the two hydrogen atoms. This is not the case when one of the hydrogen bonds is significantly stronger than the other one (case of $\mathrm{O} 2$ and $\mathrm{O} 3$ ).

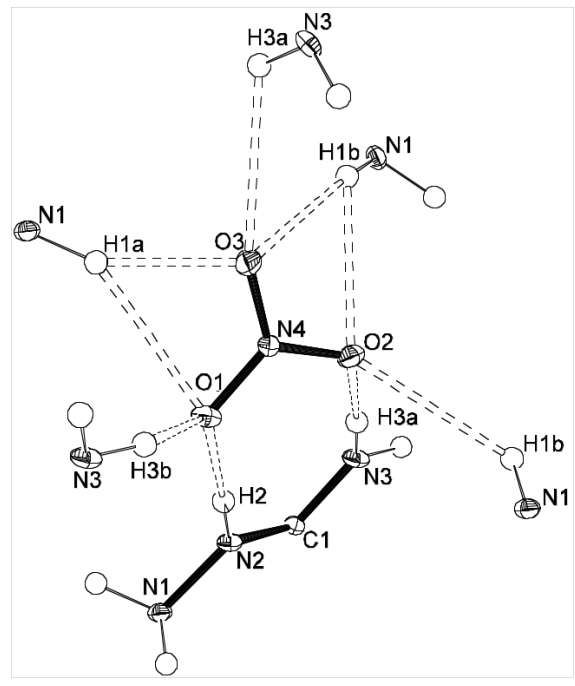

Figure 6. Space distribution of the donor atoms around the nitrate acceptor.

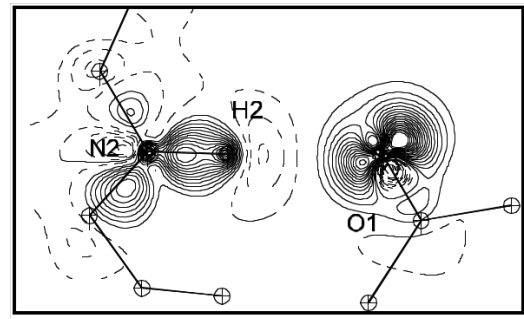

(a1)

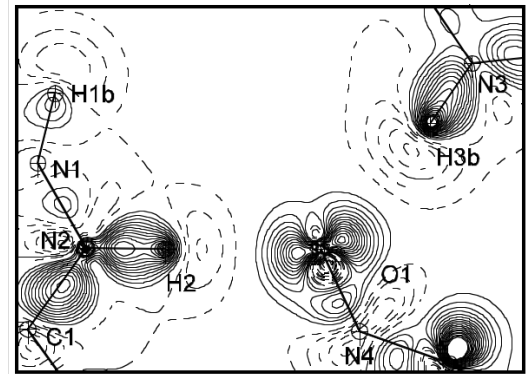

(b1)

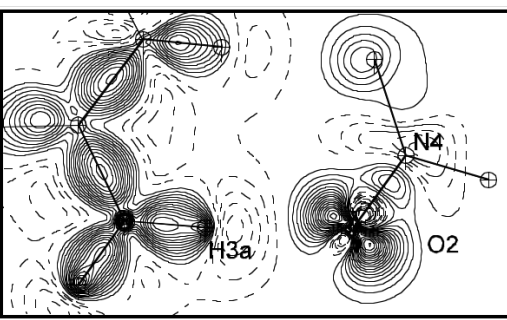

(a2)

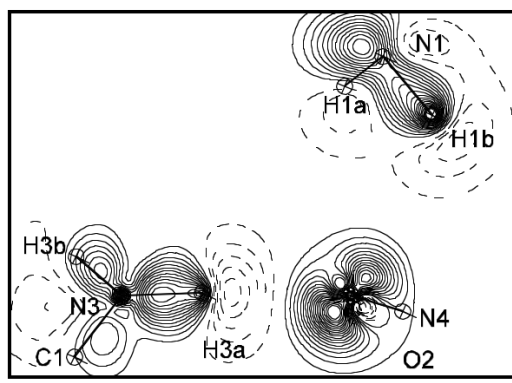

(b2)

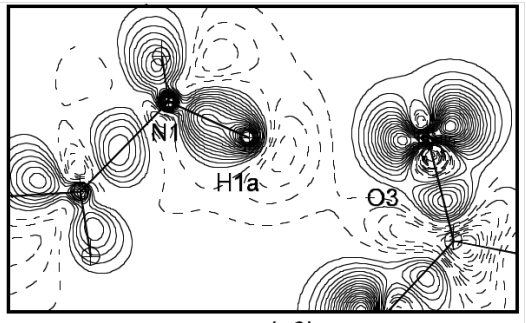

(a3)

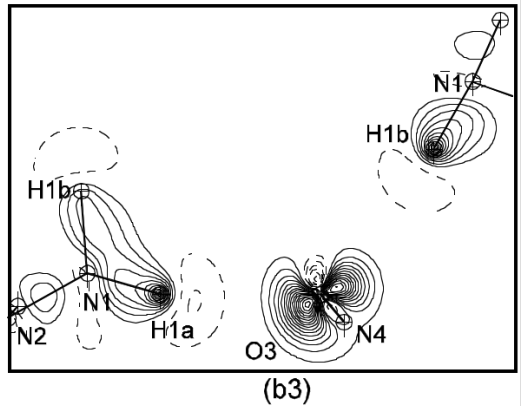

Figure 7. Hydrogen bonds static electron deformation density maps: (a) The maps are plotted in the plane containing the strongest hydrogen bond connected respectively to $\mathrm{O} 1, \mathrm{O} 2$ and $\mathrm{O} 3$; (b) The maps are plotted in the plane defined by the oxygen atom and the pair of hydrogen atoms which form two strongest hydrogen bonds. The contour interval is $0.05 \mathrm{e} \cdot \AA^{-3}$ 
The topological analysis gives a reliable quantitative description of the hydrogen bonds. The bond critical points have been found for each of the nine interactions and the corresponding parameters are given in Table 4. The first two BCP's (first two lines of Table 4) correspond to the shortest and the strongest complementary hydrogen bonds. Although slightly stronger according to its geometrical parameters, the N3-H3a...O2 hydrogen bond shows lower value of the electron density comparing to the other bond from the complementary pair $(\mathrm{N} 2-\mathrm{H} 2 \ldots \mathrm{O} 1)$. However, due to the higher value of the Laplacian the resulting kinetic energy density for $\mathrm{N} 3-\mathrm{H} 3 \mathrm{a} . . . \mathrm{O} 2$ interaction prevails in magnitude. It should be noticed that $\mathrm{N} 3-\mathrm{H} 3 \mathrm{a} . . . \mathrm{O} 2$ is bifurcated hydrogen bond since the H3a is also engaged in the weakest hydrogen bond to $\mathrm{O} 3$. On the contrary, the $\mathrm{N} 2-\mathrm{H} 2$ fragment is involved in interaction to the single O1 donor (Figure 7).

It is worth to point out some marked similarities concerning the topology of these bonds. Analyzing the acceptor site, we can find rather equivalent topological parameters for $\mathrm{N}-\mathrm{O}$ bonds whose oxygen atoms are involved in complementary hydrogen bonding. The N4-O1 and N4-O2 bonds have relatively similar lengths (1.2561(2) and 1.2568(3) A respectively) which are evidently longer than that of the N4O3 bond $(1.2418(3) \AA)$. The corresponding values of the electron density are similar $(\rho=3.07$ and 3.08 $\mathrm{e} \cdot \AA^{-3}$ for N4-O1 and N4-O2 bond respectively) and lower than in the case of the third bond $(\rho=3.20$ $\mathrm{e} \cdot \AA^{-3}$ for N4-O3) while the values of the Laplacian's $\left(-5.83\right.$ and $\left.-6.03 \mathrm{e} \cdot \AA^{-5}\right)$ are nearly half of that found for the third bond $\left(-10.82 \mathrm{e} \cdot \AA^{-5}\right)$. The ellipticities for N4-O1 and N4-O2 are identical (0.13) and again quite smaller than in the case of the third bond (0.17).

Considering the donors' sites, the N-H bonds lengths are similar within the standard uncertainties. The BCP in these bonds are found at a similar distance from the $\mathrm{H}$ atoms $(0.25 \AA)$ and exhibit the similar amounts of the electron density (2.12 and $2.14 \mathrm{e} \cdot \AA^{-3}$ for N2-H2 and N3-H3a respectively). Finally BCP's of hydrogen bonds are positioned on the almost identical distances from the oxygen acceptors $(1.30 \AA)$. The main difference regarding the position of BCP's of the two complementary hydrogen bonds arises in the H...BCP distances which differ for about $0.075 \AA$. A comparison of the 
H...O-N4 angles for these two bonds, shows that, in the case of the shorter H3a...BCP distance (N3$\mathrm{H} 3 \mathrm{a} . . . \mathrm{O} 2$ bond), this angle is $120.3^{\circ}$ which is very close to the position of the free electron pair in $s p^{2}$ hybridized oxygen. In the second bond, the corresponding $\mathrm{H} 2 \ldots \mathrm{O} 1-\mathrm{N} 4$ angle is quite smaller, $112.6^{\circ}$. One of the reasons could be an additional engagement of the $\mathrm{O} 1$ atom in the other relatively strong N3H3b...O1 hydrogen bonds which connect the formed ribbons into the two-dimensional structures. In contrast to $\mathrm{O} 1$ the further engagement of $\mathrm{O} 2$ atom in hydrogen bonding implies much weaker N1$\mathrm{H} 1 \mathrm{~b} \ldots \mathrm{O} 2$ interaction. Generally, each of the oxygen atoms is involved in three hydrogen bonds of various strengths. Considering that most of the hydrogen atoms are involved in more than one hydrogen bond there is a rather continuous dependence of the $d(N \ldots H)$ versus $G$ as suggested by Espinosa and coworkers. $^{39}$

\section{Net atomic charges}

Table 5. Net atomic charges.

\begin{tabular}{|c|c|c|c|}
\hline ATOM & Kappa & AIM & Net atomic charges derived from $x$-model ${ }^{13 a}$ and integration over th \\
\hline Zn1 & $1.45(4)$ & 0.61 & atomic basins ${ }^{22}$ are given in Table 5 . The different partitioning methods \\
\hline S1 & $0.01(5)$ & 0.12 & cause the differences between the obtained values; however the general \\
\hline N1 & $-0.70(8)$ & -0.73 & \\
\hline N2 & $-0.24(7)$ & -0.83 & trend is roughly the same. The nitrogen atoms of the TSC ligand are c \\
\hline N3 & $-0.99(9)$ & -1.22 & negatively charged, with the lowest value found for the terminal thioamide \\
\hline N4 & $0.62(5)$ & 0.65 & $\mathrm{~N} 3$ atom. The thioamide $\mathrm{C} 1$ atom, which is placed between the two \\
\hline C1 & $0.15(8)$ & 0.73 & electronegative nitrogen and the sulfur atoms is positively charged. The \\
\hline 01 & $-0.59(4)$ & -0.54 & hydrogen atoms provide the rest of the positive charge of the chelate ligand. \\
\hline $\mathbf{O 2}$ & $-0.45(4)$ & -0.56 & \\
\hline $\mathbf{O 3}$ & $-0.53(4)$ & -0.57 & Among the hydrogen atoms, those attached to the thioamide $\mathrm{N} 3$ are the most \\
\hline H1a & $0.38(5)$ & 0.53 & positively charged. Both analyses also show that the $S$ atom is the least \\
\hline H1b & $0.37(5)$ & 0.45 & charged atom in the structure. The charges of the nitrate anion obtained by \\
\hline $\mathbf{H} 2$ & $0.28(5)$ & 0.50 & two different methods are real, $\mathrm{q}\left(\mathrm{NO}_{3}\right)_{\varkappa}=-0.95(10)$ e and $\mathrm{q}\left(\mathrm{NO}_{3}\right)_{\mathrm{AIM}}=-1.02$ \\
\hline H3a & $0.45(6)$ & 0.59 & \\
\hline H3b & $0.53(5)$ & 0.58 & e. \\
\hline
\end{tabular}


The more significant difference between two groups of charges emerges if we compare the relative distribution of the positive charge between the Zn atom and TSC ligands. Namely, the $x$-model yielded to the high value of charge for $\mathrm{Zn}$ atom equal to $+1.45(4)$ e. In this case the $\mathrm{Zn}$ atom represents the center of the positive charge, since the each TSC ligand is carrying much less positive charge of $+0.24(20)$. According to AIM method the positive charge is more dissipated within the cation which resulted in relatively low positive charge for $\mathrm{Zn}$ atom of $+0.61 \mathrm{e}$, while the charge of TSC ligand is higher and equal to +0.72 e. Such a low integrated charge for the $\mathrm{Zn}$ basin could be the consequence of the specific Zn-ligand interaction, which in contrast to the other metal ions does not involve d orbital. Namely, in the case of the title compound the Zn atom has fully occupied $d$ orbitals and thus only $4 s$ introduced in the metal ligand interaction. Since the $4 s$ orbital is very diffuse in the direct space it is possible that the charge of $\mathrm{Zn}$ is spread out over the ligand i.e. not localized as a non-zero $3 d$ electron occupation usually is. Consequently the net charge integrated over the $\mathrm{Zn}$ basin is low.

In order to check this explanation, the AIM charges of the $\left[\mathrm{Zn}(\text { aspirinate })_{2}\left(\mathrm{H}_{2} \mathrm{O}\right)_{2}\right]$ compound ${ }^{17}$ have been determined. The trends above described observed in the $\left[\mathrm{Zn}(\mathrm{TSC})_{2}\right]\left(\mathrm{NO}_{3}\right)_{2}$ remain in the second complex $\left[\mathrm{Zn}(\text { aspirinate })_{2}\left(\mathrm{H}_{2} \mathrm{O}\right)_{2}\right]\left(\mathrm{q}(\mathrm{Zn})_{\varkappa}=+1,8(1)\right.$ and $\left.\mathrm{q}(\mathrm{Zn})_{\mathrm{AIM}}=+1.00 \mathrm{e}\right)$. The net atomic charges obtained by a $x$-refinement, when the tetrahedral $\mathrm{Zn}$ is modelized as $d^{10}$ are closer than the net charge obtained for the third octahedral complex $\left[\mathrm{Zn}\left(\mathrm{C}_{4} \mathrm{O}_{4}\right)\left(\mathrm{H}_{2} \mathrm{O}\right)_{4}\right]$ when the $d$ orbitals are refined $(+1.97 \mathrm{e}){ }^{16}$

\section{Electrostatic potential}

In addition to the analysis of the electron density distribution, we also derived the electrostatic potential $(\mathrm{EP})$ of $\left[\mathrm{Zn}(\mathrm{TSC})_{2}\right]\left(\mathrm{NO}_{3}\right)_{2}$ in attempt to get a better understanding of its further chemical reactivity. In this analysis we focused only on the EP generated on the surface on the complex cation. We employed the MOLEKEL graphic tool ${ }^{40}$ to distinguish between the fine differences in positive EP.

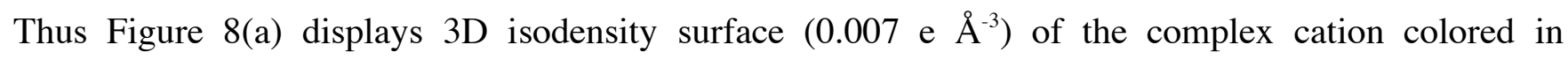


accordance with the EP determined on the basis of data obtained after the multipole refinement. Beside the EP of the complex cation isolated from the crystalline environment, we also present the features of the EP of the isolated gas phase cation obtained by the quantum mechanical calculation (Figure 8(b)).

The less positive EP coincides with the conjugated thioureide fragment (Figure 8(a)). One of the two least positive EP regions is found in the surroundings of $\mathrm{S}$ atom (A). The part of the cation surface close to Zn exhibits the middle value of the overall positive EP (B). The second EP minimum (the least positive value) on the complex surface is found in the vicinity of the terminal nitrogen N3, which is also reported as the most negative atom in this structure $(\mathbf{C})$. Starting from this region with the least positive EP, the positive EP increases through the number of successive narrow regions of EP magnitudes (D), finally reaching the highest positive value in the vicinity of the hydrogen atoms attached to N1 donor (E). The positive contribution of the central metal ion to the EP also appears on the surface of the complex cation $(\mathbf{F})$.
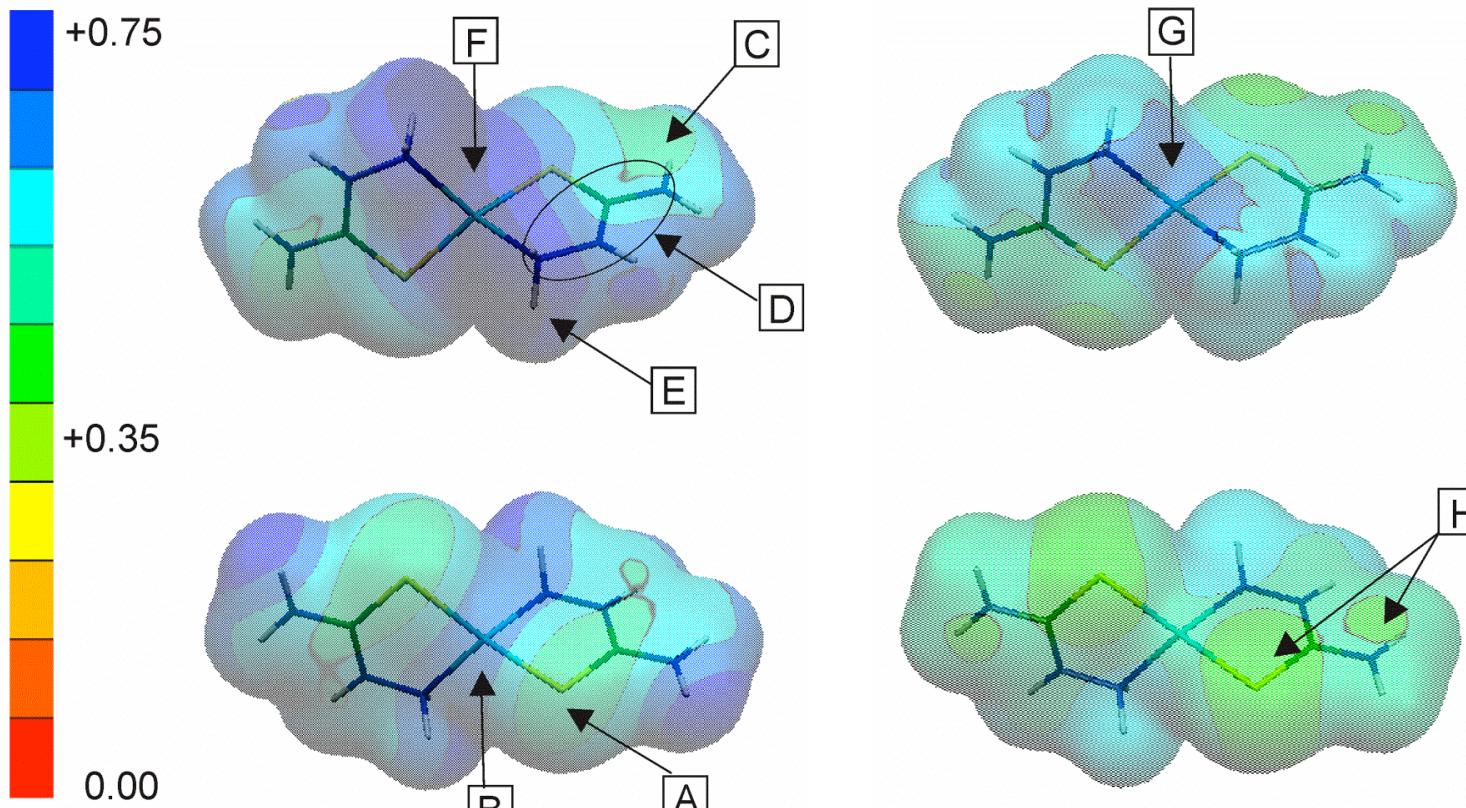

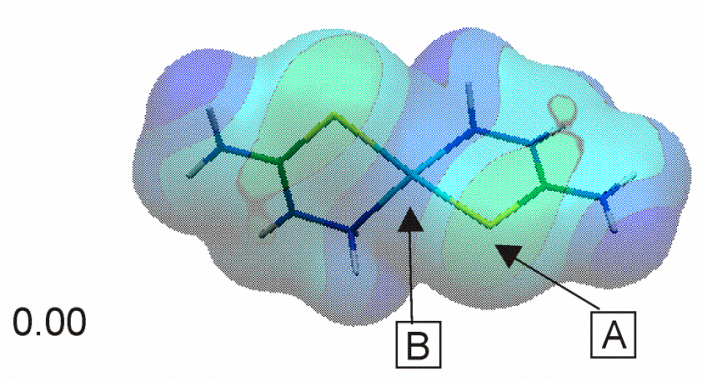

(a)

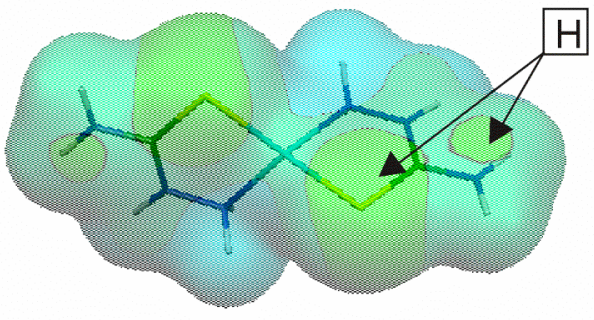

(b)

Figure 8. EP $\left(e \cdot \AA^{-1}\right)$ generated on the cationic three-dimensional isodensity surface $\left(0.007\right.$ e. $\left.\AA^{-3}\right):(a)$ experimental; (b) theoretical (DFT). 
As previously mentioned, $\left[\mathrm{Zn}(\mathrm{TSC})_{2}\right]\left(\mathrm{NO}_{3}\right)_{2}$ complex, together with some dicarboxylic salts has been used as the reactant in the synthesis of several supramolecular structures. ${ }^{9 \mathrm{a}, \mathrm{g}, \mathrm{d}}$ In each of these structures, $\mathrm{Zn}$ atom within a corresponding cationic TSC building block increases its coordination number to 5 or 6 , in contrast to nickel building block, $\left[\mathrm{Ni}(\mathrm{TSC})_{2}\right]^{2+}$ which often preserves its original coordination number of $4 .^{9 b, \mathrm{~h}, 10 \mathrm{a}}$ The rather nucleophic zone $(\mathbf{F})$ could be responsible for the increasement of the coordination number of $\mathrm{Zn}$ in the synthesis of the complexes entering the mentioned supramolecular structures.

The theoretically EP agrees rather well with the described experimentally derived properties for $\left[\mathrm{Zn}(\mathrm{TSC})_{2}\right]^{2+}$ cation (Figure 8(b)). The complex cation in the gas phase still retains nucleophilic zone above the $\mathrm{Zn}$ atom $(\mathbf{G})$, suggesting that it is not the result of the influence of the surrounding anions in crystal packing. The least positive EP is again found in the region of the $\mathrm{S}$ and N3 atoms $(\mathbf{H})$. Due to the absence of the influence of the crystalline environment the EP minima are more symmetrically distributed. These trends remain in the two cations $\left[\mathrm{Zn}(\mathrm{TSC})_{2}\left(\mathrm{H}_{2} \mathrm{O}\right)_{2}\right]($ tere $),{ }^{9 \mathrm{~g}}\left[\mathrm{Zn}(\mathrm{TSC})_{2}\left(\mathrm{H}_{2} \mathrm{O}\right)_{2}\right]($ fum $),{ }^{9 \mathrm{~d}}$ for which the theoretical EP has been computed based on the room crystal structure geometry, while they are less expressed. The presence of the water molecules leading to an $\mathrm{O}_{h}$ symmetry for the $\mathrm{Zn}$ atom, does not significantly influence the EP value nearby the TSC ligand. 


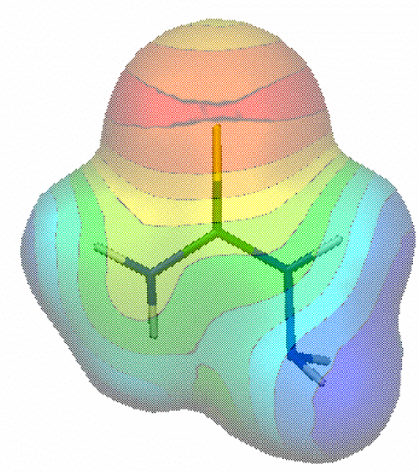

(a)

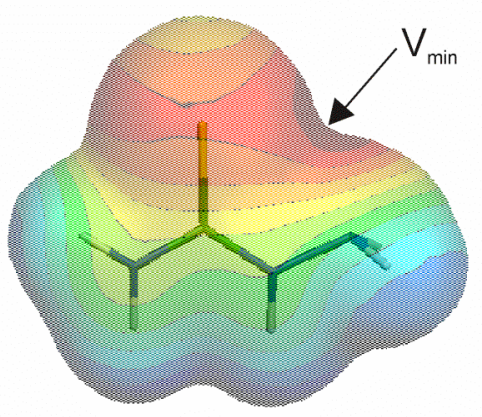

(b)

Figure 9. Theoretically determined EP $\left(e \cdot \AA^{-1}\right)$ generated on the three-dimensional isodensity surface $\left(0.007 \mathrm{e} \cdot \AA^{-3}\right)$ of the TSC ligand in: (a) trans; (b) cis-configuration.

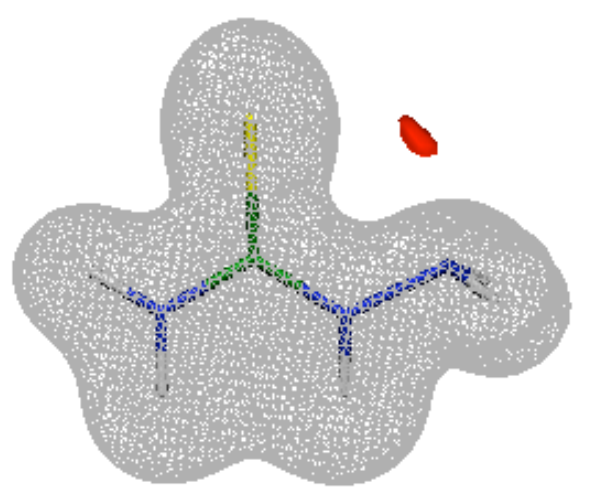

Figure 10. Three-dimensional isopotential surfaces of the coordinated form (cis) of the TSC ligand; Grey and red correspond to $\mathrm{V}_{\max }=+0.18$ and $\mathrm{V}_{\min }=-0.18 \mathrm{e} \cdot \AA^{-1}$, respectively.

To investigate the coordination abilities of the TSC ligand alone we have further used the quantumchemical calculation $^{29}$ to explore the distribution of the EP within two different forms of this molecule. The trans form of the TSC molecule ${ }^{30}$ is present in the solid state and thus corresponds to the molecule 
which is entering the complex synthesis. In this uncoordinated form the atoms $\mathrm{S} 1$ and N1 are placed on the opposite sides regarding the C1-N2 bond. According to the EP distribution represented in Figure 9 (a), we can assume that in trans configuration of the TSC, the sulfur atom surrounded with the most negative EP, represents the only relevant center of the nucleophile attack and thus the coordination to the central metal ion. The monodentate coordination of the TSC is rare, but in some complexes of $\mathrm{Ag}$ the coordination is realized via $\mathrm{S}$ atom. ${ }^{41}$ To achieve more stable bidentate coordination which is also favored by chelate effect, the only available atom is N1 as it has the free electron pair. The engagement of the N1 is also geometrically favorable due to the formation of the very stable five-membered chelate ring. The NS bidentate coordination and the formation of the five membered chelate is a basic property of almost all TSC based compounds. ${ }^{5}$ The distribution of the EP within the cis form of the TSC ligand present in the complexes is given in Figure 9 (b). It is obvious that in comparison with the trans configuration (Figure 9 (a)) the minimum of the EP is shifted from the S atom toward the place where the binding of cental metal ion is expected. This minimum is much deeper than that existing on the $\mathrm{S}$ atom in trans form due to the contribution of the free electron pair of the N1 atom. Figure 10 represent the isopotential surface of the coordinted form of TSC which confirms that the EP minimum is located exactly between the donor atoms in the place of the metal coordination. It is worth mentioning that cis configuration of TSC present in the complexes also causes the redistribution of the positive EP generated by its hydrogen atoms. The positive EP of the ligand is joined into a broad region (Figure 9(b)) which in formed bis(TSC) compounds (takes the lateral sides and) symmetrically surrounds the complex unit. In the presence of the appropriate hydrogen bonding acceptor this unit becomes defined building block as is the case with the above mentioned supramolecular structures.

\section{Topology of the electrostatic potential}




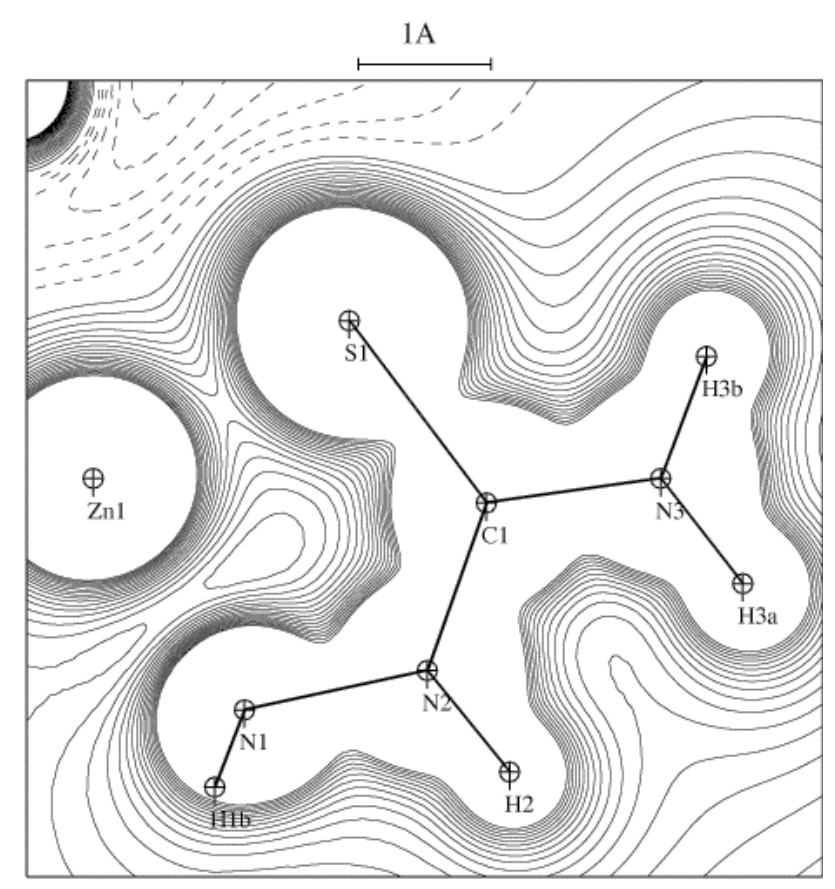

(a)

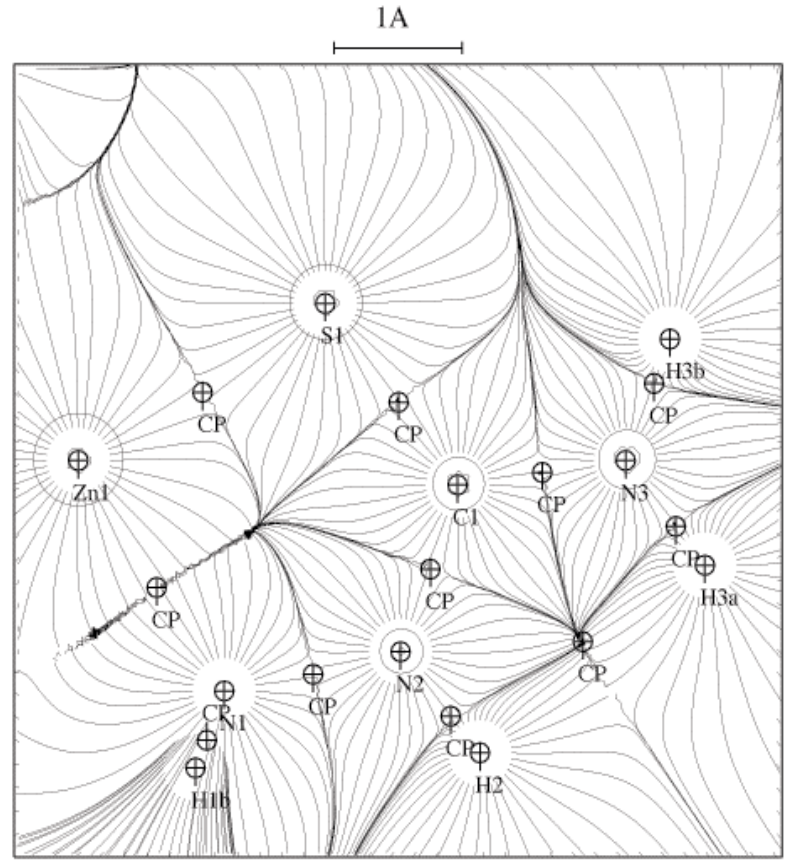

(b)

Figure 11. (a) Electrostatic potential in the Zn-TSC ligand plane. Contour intervals $0.05 \mathrm{e}^{-1}$; negative contours are dashed, zero contour omitted. (b) Electric field lines in the same plane. Critical points are indicated as "CP".

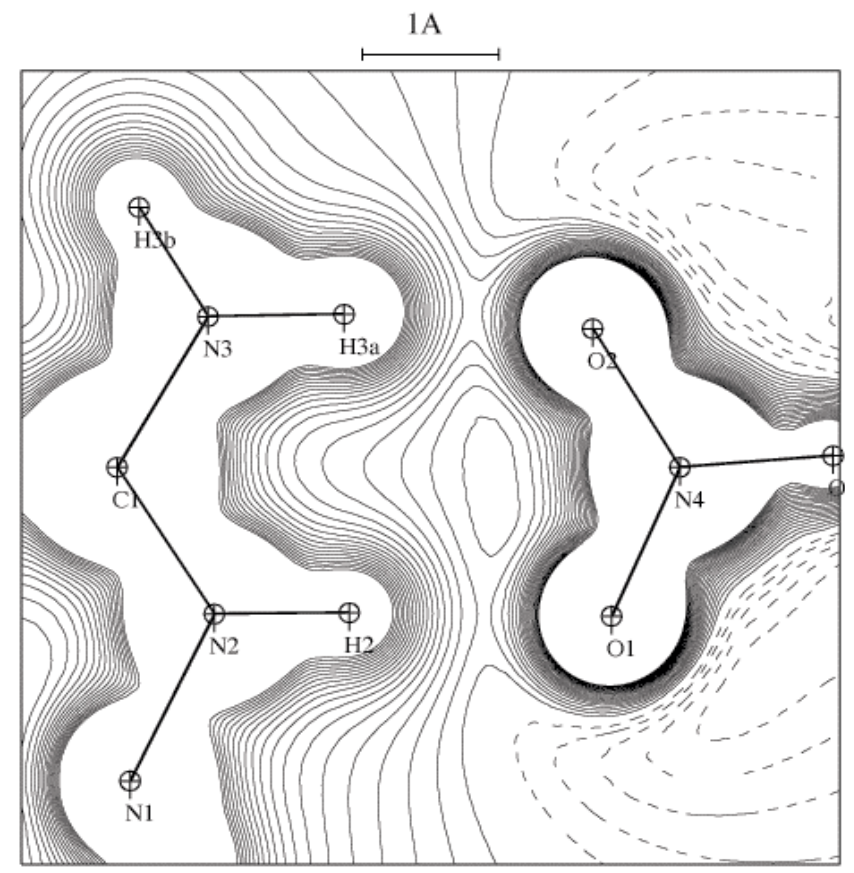

(a)

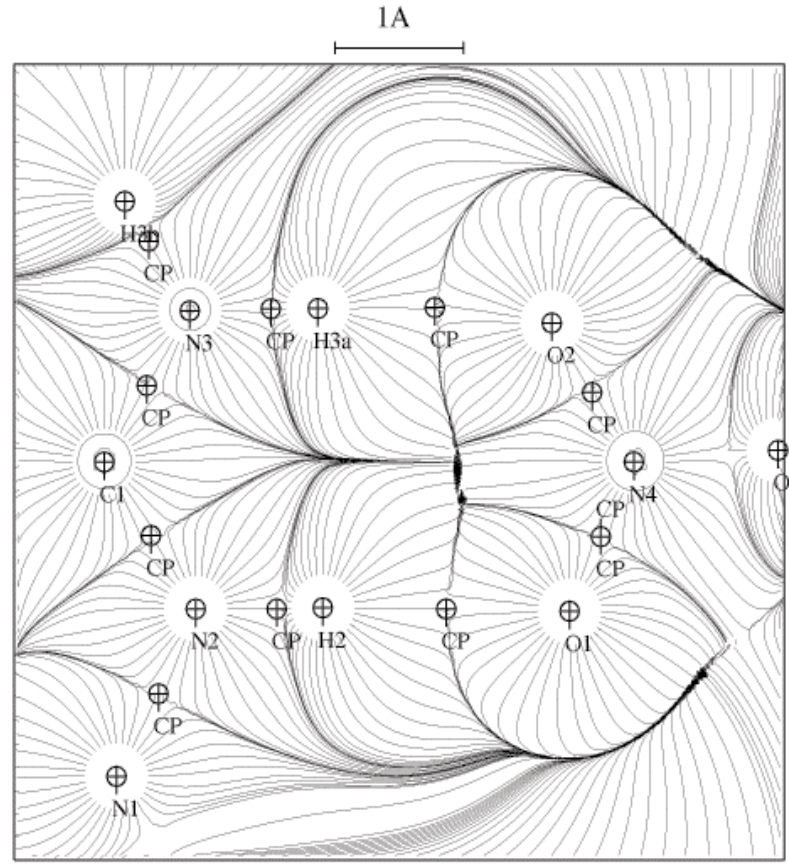

(b) 
Figure 12. (a) Electrostatic potential in the $\mathrm{TSC}-\mathrm{NO}_{3}$ double hydrogen bonds plane. Contour intervals $0.05 \mathrm{e}^{-1}$; negative contours are dashed, zero contour omitted. (b) Electric field lines in the same plane. Critical points are indicated as "CP".

The electrostatic potential $\mathrm{V}(\mathbf{r})$ (hereafter EP) is one of the derived properties that is directly related to the reactivity of molecules. ${ }^{13 a, 42}$ Electrophilic and nucleophilic regions are easily revealed and can serve for the quantitative electrostatic characterization of the chemical system and for the chemical activity prediction as well. Topographical characteristics of the EP are complementary to those of the electron density. The gradient $\mathbf{E}(\mathbf{r})=-\nabla \mathrm{V}(\mathbf{r})$ of EP, that is the electric field, can be calculated analytically from the Hansen-Coppens model used in the experimental electron density refinement. ${ }^{33}$ Based on this model, two of the authors have developed the FIELD program for the calculation and visualization of the electric field lines around the molecules. ${ }^{43}$ As for the electron density, the molecular space is partitioned in pseudo-atomic basins or volumes delimited by the zero flux surfaces of the electric field. These correspond to electro-neutral space units in which the electron density concentrates in order to screen the positive contribution of the nuclear charges to the EP. In contrary to the electron density $\rho(\mathbf{r})$ which is a local property and positive everywhere around the chemical system, EP can be a sharp function that changes its sign in particular regions where the electronic concentration dominates. This gives rise to open basins for positive atoms like peripheral hydrogen's and closed and smallest ones for electronegative atoms like $\mathrm{O}$ and $\mathrm{N}$. We emphasize here that these basins correspond to neutral charges while those of electron density gradient define the atomic volume in the molecule and therefore its charge transfert. The electric field and electron density gradient offer complementary physic methods to separate the intramolecular space between atoms and therefore the corresponding atomic basins ovelap. The topology of EP also displays critical points (CP's positioned by a vector $\mathbf{r}_{\mathrm{cp}}$ in the unit cell) similar to those of the electron density: $(3,-1)$ saddle, $(3,-3)$ local maximum, $(3,+3)$ local minimum but also ring $(3,+1)$ CP's and so on. 3 is here the number of non zero eigenvalues $\lambda_{1}, \lambda_{2}, \lambda_{3}$ of the Hessian matrix of $\mathrm{V}(\mathbf{r})$ and the second numbers $-3,-1,+1$ and +3 are the sum of the algebraic signs of $\lambda_{\mathrm{i}}$. The 
eigenvector associated to $\lambda_{3}$ is conventionally chosen along the atomic link. The Poisson's equation $\nabla^{2} \mathrm{~V}(\mathbf{r})=-4 \pi \rho(\mathbf{r})$ is valid everywhere inside or outside the chemical system and relates the two properties. Saddle $(3,-1)$ CP's are generally found between a pair of covalently bonding atoms or in hydrogen bonds. At these positions, the electric field and thus the electric force on a probe charge vanishes showing the balance between the two screened nuclear charges. As also remembered by Tsirelson et $a l,{ }^{44}$ the electrostatic energy density proportional to the square of the electric field modulus reaches zero at all critical points.

Figure 11(a) displays the EP calculated in the plane containing the Zn cation and the TSC ligand. As can be expected for a cationic entity, the EP is positive in the vicinity of the metal-ligand complex. On the top-left of Figure 11(a), the negative region (with a minimum of $-0.3 \mathrm{e} \AA^{-1}$ ) is due to the proximity of the $\mathrm{NO}_{3}{ }^{-}$anion. In the same plane, Figure 11(b) depicts the electric field lines generated by the $\mathrm{Zn}$-TSC complex. In the plane of this figure, all CP's are of $(3,-1)$ kind except two $(3,+1)$ ring $\mathrm{CP}$ found between $\mathrm{H} 2$ and $\mathrm{H} 3 \mathrm{a}$ (folding induced $\mathrm{CP}$ ) and that corresponding to the Zn1-S1-C1-N2-N1 ring here under the considered plane. As previously mentioned, the gradient vector lines define closed and open atomic basins with different shapes, structures and sizes. Internal atoms like C1, N2 and N3 display triangularly-shaped closed basins whereas peripheral $\mathrm{H} 2, \mathrm{H} 3 \mathrm{a}$ and $\mathrm{H} 3 \mathrm{~b}$ have extended basins. It is worthy to note that $\mathrm{S} 1$ sulfur atom has the largest basin even when compared to that of the metal. This is in agreement with the almost neutral net charge reported in the previous section for S1 which behaves as an isolated atom with a dominating nuclear charge contribution to the EP. Another interesting plane is that containing the double hydrogen bond occurring between the TSC ligand and $\mathrm{NO}_{3}^{-}$anion. EP features are shown in Figure 12(a) and the electric field lines in Figure 12(b). In addition to the inner (3, -1) CP's of the TSC ligand, those characterizing the $\mathrm{N} 2-\mathrm{H} 2 \cdots \mathrm{O} 1$ and $\mathrm{N} 3-\mathrm{H} 3 \mathrm{a} \cdots \mathrm{O} 2$ hydrogen bonds are now appearing in Figure 12(b).

Table 6 gives the topographical features of the EP generated around the Zn-TSC complex. As pointed out in prior electric field $\mathrm{study}^{43}$, the $\mathrm{CP}$ atomic distances define the van der Waals radii. In 
exception of the N1-N2 bond, all others are heteroatomic links. That means that the contributions of the nuclear charges to the EP are in principle dissymmetrical. That holds particularly true for $\mathrm{N}-\mathrm{H}$ bonds where the $\mathrm{CP}$ is pushed toward the $\mathrm{H}$ atoms $(<\mathrm{d} 1>=0.63 \AA$ and $\quad<\mathrm{d} 2>=0.36 \AA)$ and for $\mathrm{C} 1-\mathrm{S} 1(\mathrm{~d} 1=$ $0.78 \AA$ and $\mathrm{d} 2=0.94 \AA$ ). However, for all other bonds, even for $\mathrm{Zn}-\mathrm{N}$ and $\mathrm{Zn}-\mathrm{S}$, CP's are located approximately at the midpoint of the atomic link. It's worthy to note that each atom shows directionally van der Waals radii referring to the type of bonds and atoms involved in. In Table 6 are also reported the values of $\rho\left(\mathbf{r}_{\mathrm{cp}}\right)$ and $\mathrm{V}\left(\mathbf{r}_{\mathrm{cp}}\right)$ for each bond. For all covalent bonds, these values are greater than unity reflecting here the electron accumulation and the positive high value of potential at the vicinity of the nuclei. The Zn1-N1 and Zn1-S1 corresponding values are however weak and are almost of the same order of magnitude of hydrogen bonds reported in Table 6. It is an expected result since only the diffuse $4 s$ orbital of the metal is involved in the interaction with the ligand and the $3 d$ shell was found unperturbed. In the last part of Table 6, the hydrogen bond characteristics of the title complex are given. The accumulation of the electron density at the CP's is in the range of 0.2 to $0.3 \mathrm{e}^{-3}$. However, we can note that for the two last longer bonds $(\mathrm{H} \ldots \mathrm{O} \geq 2 \AA), \mathrm{V}\left(\mathbf{r}_{\mathrm{cp}}\right)$ becomes negative. The eigenvalues of the

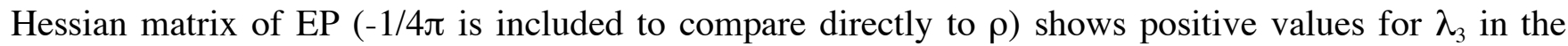
bond direction and negative values in the perpendicular ones. According to Poisson's equation, that is $\rho\left(\mathbf{r}_{\mathrm{cp}}\right)=\lambda_{1}+\lambda_{2}+\lambda_{3}$, these values reflect the electron density accumulation $\left(\lambda_{\mathrm{i}}\right.$ positive $) /$ depletion $\left(\lambda_{\mathrm{i}}\right.$ negative) at the EP critical points. As expected the $\lambda_{3}$ is higher than $\lambda_{1}$ or $\lambda_{2}$ which correspond to axial symmetry of electron density when $\lambda_{1}=\lambda_{2}$.

Table 6. Topological properties of the electrostatic potential for the covalent bonds and the hydrogen bonds

\begin{tabular}{|l|l|l|l|l|l|l|l|}
\hline Bond & $\mathrm{d} 1$ & $\mathrm{~d} 2$ & $\rho\left(\mathrm{r}_{\mathrm{cp}}\right)$ & $\lambda_{1}$ & $\lambda_{2}$ & $\lambda_{3}$ & $\mathrm{~V}\left(\mathrm{r}_{\mathrm{cp}}\right)$ \\
\hline Zn1-N1 & 1.155 & 0.945 & 0.632 & -0.062 & -0.029 & 0.723 & 0.225 \\
Zn1-S1 & 1.102 & 1.174 & 0.404 & -0.129 & -0.117 & 0.650 & 0.463 \\
N1-N2 & 0.707 & 0.706 & 2.128 & -0.911 & -0.867 & 3.905 & 1.670 \\
\hline \hline
\end{tabular}




\begin{tabular}{|l|l|l|l|l|l|l|l|}
\hline C1-N2 & 0.674 & 0.668 & 2.535 & -1.124 & -0.991 & 4.650 & 1.874 \\
C1-N3 & 0.668 & 0.659 & 2.622 & -1.183 & -1.029 & 4.834 & 1.900 \\
C1-S1 & 0.776 & 0.944 & 1.459 & -0.505 & -0.439 & 2.403 & 1.204 \\
O1-N4 & 0.624 & 0.632 & 3.119 & -1.610 & -1.587 & 6.317 & 1.974 \\
O2-N4 & 0.625 & 0.631 & 3.141 & -1.608 & -1.575 & 6.324 & 2.000 \\
O3-N4 & 0.617 & 0.625 & 3.186 & -1.719 & -1.681 & 6.586 & 2.003 \\
N1-H1a & 0.632 & 0.365 & 2.340 & -2.038 & -1.936 & 6.314 & 2.104 \\
N1-H1b & 0.653 & 0.377 & 2.198 & -1.775 & -1.689 & 5.662 & 1.869 \\
N2-H2 & 0.629 & 0.361 & 2.329 & -2.141 & -2.004 & 6.474 & 2.169 \\
N3-H3a & 0.635 & 0.371 & 2.366 & -1.951 & -1.845 & 6.162 & 1.991 \\
N3-H3b & 0.625 & 0.359 & 2.438 & -2.147 & -2.039 & 6.624 & 2.085 \\
\hline H-bonds & $\mathrm{d} 1$ & $\mathrm{~d} 2$ & $\rho\left(\mathrm{r}_{\mathrm{cp}}\right)$ & $\lambda_{1}$ & $\lambda_{2}$ & $\lambda_{3}$ & $\mathrm{~V}\left(\mathrm{r}_{\mathrm{cp}}\right)$ \\
\hline N3-H3a...O2 & 0.921 & 0.930 & 0.347 & -0.128 & -0.102 & 0.577 & 0.245 \\
N2-H2...O1 & 0.963 & 0.962 & 0.308 & -0.092 & -0.070 & 0.471 & 0.131 \\
N1-H1a...O3 & 1.040 & 0.960 & 0.304 & -0.080 & -0.060 & 0.444 & 0.085 \\
N3-H3b...O1 & 1.118 & 0.975 & 0.269 & -0.081 & -0.061 & 0.411 & -0.044 \\
\hline
\end{tabular}

According to Hellman-Feynman theorem, ${ }^{45}$ the electric field at the nuclear positions is zero $((3,-3)$ CP's) but EP does not vanish. The values of EP at these particular points are in relation with the coreelectron binding energy. ${ }^{44}$ This is particularly interesting for the hydrogen atom with its single electron. Accordingly, Galebov and coworkers ${ }^{46}$ emphasized the usefulness of the electrostatic potential in nuclear sites (EPN corresponding to (3, -3) CP's defined above) as hydrogen bonding reactivity parameters. The authors found an excellent correlation between the theoretically determined values of EPN at the site of the hydrogen atom and the energies of the hydrogen bond formation. Considering the significant hydrogen donating capacity of $\left[\mathrm{Zn}(\mathrm{TSC})_{2}\right]^{2+}$, we decided to employ this quantity in further analysis of its hydrogen bonding features. We derived the EPN values ${ }^{33}$ for the molecule 
$\left[\mathrm{Zn}(\mathrm{TSC})_{2}\right]\left(\mathrm{NO}_{3}\right)_{2}$ extracted from the crystalline environment on the basis of the experimental data obtained after the multipole refinement (Table 7, (1)). In addition, we determined the values of EPN for isolated gas phase molecule $\left[\mathrm{Zn}(\mathrm{TSC})_{2}\right]\left(\mathrm{NO}_{3}\right)_{2}(2)$ and its cation $\left[\mathrm{Zn}(\mathrm{TSC})_{2}\right]^{+2}$ (3) from quantum chemical calculations. The theoretical EPN values were also derived for two octahedral cations $\left[\mathrm{Zn}(\mathrm{TSC})_{2}\left(\mathrm{H}_{2} \mathrm{O}_{2}\right)\right]^{2+}$ which are real building blocks of the supramolecular structures $\left[\mathrm{Zn}(\mathrm{TSC})_{2}\left(\mathrm{H}_{2} \mathrm{O}\right)_{2}\right]($ tere $)(4),{ }^{9 \mathrm{~g}}$ and $\left[\mathrm{Zn}(\mathrm{TSC})_{2}\left(\mathrm{H}_{2} \mathrm{O}\right)_{2}\right]($ fum $)(5) .{ }^{9 \mathrm{~d}}$ Each of these structures exhibits the same feature, namely each of them forms the strongest, complementary hydrogen bonds with the same N2-H2, N3-H3a donor set. Finally, the EPN values were also calculated for different configurations of the neutral TSC ligand $(6,7)$ and for its porotonated form $\operatorname{TSCH}^{+}(\mathbf{8})$, from the corresponding chloride salt $^{31}$.

The EPN values derived for all the complex cations in the gas phase (3-5) (including the one for the title compound), follow the identical pattern. The least negative EPN value (in bold in Table 7) is found for the $\mathrm{H} 2$ atom attached to hydrazine $\mathrm{N} 2$, than follow the H1a and $\mathrm{H} 1 \mathrm{~b}$ attached to coordinated hydrazine N1, and finally $\mathrm{H} 3 \mathrm{a}$ and $\mathrm{H} 3 \mathrm{~b}$ from the thioamide N3. This should be an indication of the hydrogen's reactivity toward the hydrogen bond formation (pattern, sequence) and an indication of the relative strength of the formed hydrogen bonds and therefore their corresponding bond energies. According to these results, in each of these cations, the $\mathrm{H} 2$ atom shows the highest affinity for hydrogen bonding. This atom is the one which is involved in complementary hydrogen bonding; however its pair H3a has a more negative EPN value meaning that its tendency to form the hydrogen bonds is slightly less than for hydrogen's attached to N1. Despite these arguments, in the above mentioned crystal packings of $\left[\mathrm{Zn}(\mathrm{TSC})_{2}\right]\left(\mathrm{NO}_{3}\right)_{2},\left[\mathrm{Zn}(\mathrm{TSC})_{2}\left(\mathrm{H}_{2} \mathrm{O}\right)_{2}\right](\text { tere })^{9 \mathrm{~g}}$ and $\left[\mathrm{Zn}(\mathrm{TSC})_{2}\left(\mathrm{H}_{2} \mathrm{O}\right)_{2}\right](\text { fum })^{9 \mathrm{~d}}$ the $\mathrm{H} 3 \mathrm{a}$ atom is always part of the donor set for complementary hydrogen bonding. It seems that suitable, almost parallel orientation of the H2, H3a donor set toward the corresponding acceptors (torsion H2-N2-N3$\left.\mathrm{H} 3 \mathrm{a}=6.9^{\circ}\right)$ makes the engagement of $\mathrm{H} 3 \mathrm{a}$ atom in complementary hydrogen bonds more favourable than for the atoms $\mathrm{H} 1 \mathrm{a}$ and $\mathrm{H} 1 \mathrm{~b}$ (torsion $\mathrm{H} 2-\mathrm{N} 2-\mathrm{N} 3-\mathrm{H} 1=50.9^{\circ}$ and $-66.2^{\circ}$ respectively). 
In the case of the whole $\left[\mathrm{Zn}(\mathrm{TSC})_{2}\right]\left(\mathrm{NO}_{3}\right)_{2}$ molecule in the gas phase (Table 7, (2)) the EPN values become more negative. These values are particularly decreasing for the H2, H3a atoms which form the hydrogen bonds to the present anion. The experimental EPN's (Table 7, (1)) cannot be directly compared to theoretical since they are generally lower than the gas phase values. It is interesting to note that, in contrast to the gas phase cases, the EP at the hydrogen's sites of the molecule from the crystal lattice reflects the present state of the hydrogen bonding regarding their strength. The highest EPN values are found for the $\mathrm{H} 2$ and $\mathrm{H} 3 \mathrm{a}$ donors set, then follow the $\mathrm{H} 3 \mathrm{~b}$ and $\mathrm{H} 1 \mathrm{a}$ which are involved in hydrogen bonds of similar strength and finally $\mathrm{H} 1 \mathrm{~b}$ which is engaged in the less strong N1-H1b...O3 hydrogen bond.

The EPN values of the two neutral TSC forms (Table $7(\mathbf{6})$ and (7)) are mutually similar and suggest the lower tendency of the hydrogen atoms to enter the hydrogen bonding. The protonation of the ligand (Table $7(\mathbf{8})$ ) obviously increases the EPN values of the corresponding hydrogen atoms particularly those attached to the protonated nitrogen atom. It is interesting to notice that the EPN values of the listed complex cations (3-5) are similar to those found for the protonated ligand. The positively charged metal ion spread its charge to the coordinated ligands causing the redistribution of the electron density. This significantly increases the EPN values of the hydrogen atoms and stimulates the engagement of ligand in hydrogen bonds. It can be suggested that by coordination to the metal ion TSC ligand increase its capacity for hydrogen bonding to the level of protonated ligand. 
Table 7. EPN values (in a.u.) in the title compound (1-3), in similar supramolecular building blocks (4,5) and for different forms of the TSC ligand (6-8). The values are determined by POTNUC ${ }^{33}$ for case $\mathbf{1}$ and by Gaussian ${ }^{29}$ for cases $\mathbf{2 - 8}$. In bold the less negative EPN for hydrogen.

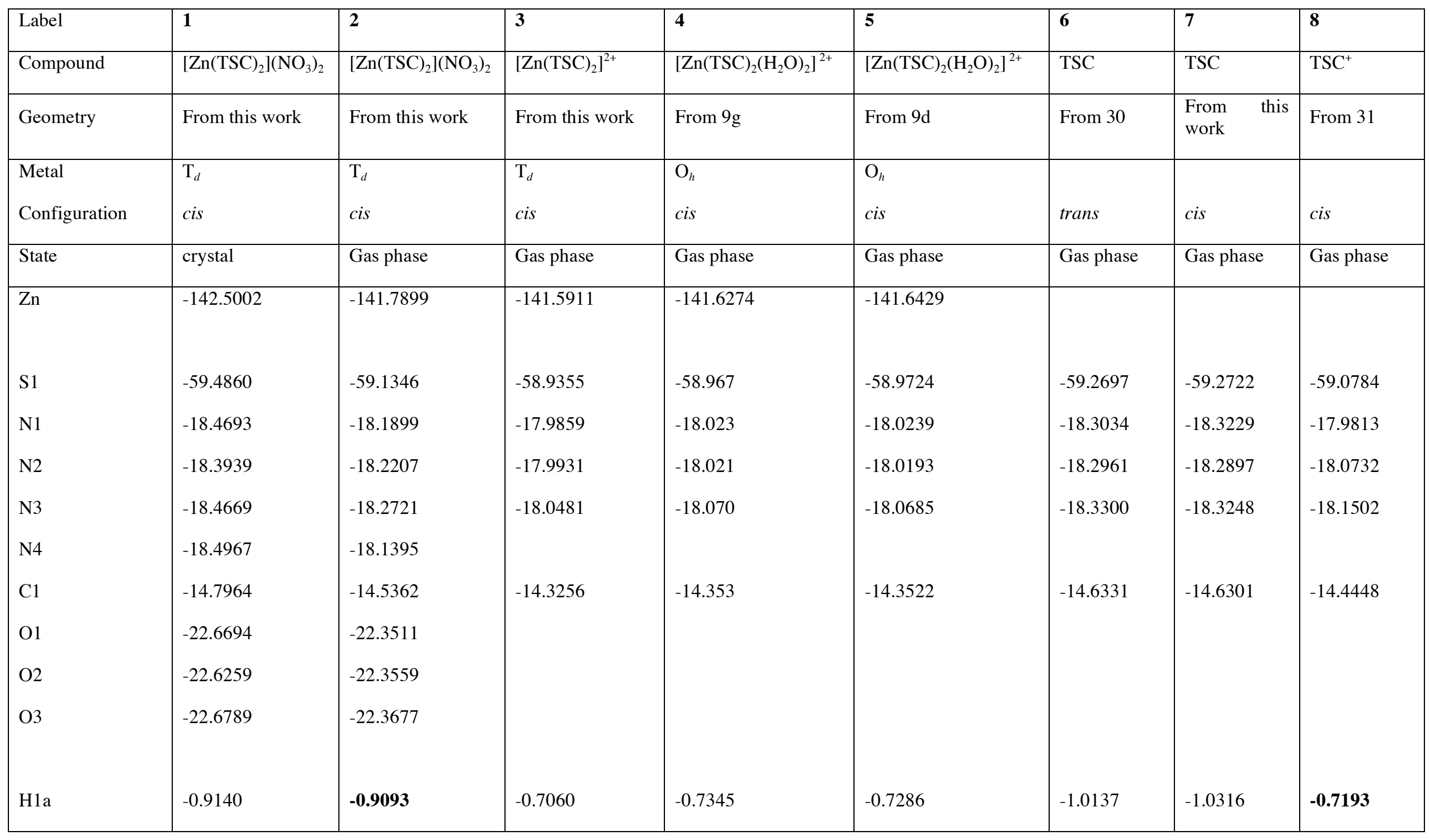




\begin{tabular}{|c|c|c|c|c|c|c|c|c|}
\hline H1b & -1.0089 & $\begin{array}{l}-0.9092 \\
\end{array}$ & -0.7066 & -0.7375 & -0.7378 & -1.0123 & -1.0320 & -0.7314 \\
\hline $\mathrm{H} 2$ & -0.8925 & -0.9389 & -0.6999 & -0.7247 & -0.7208 & -1.0008 & -0.9944 & -0.7715 \\
\hline H3a & -0.8792 & -0.9601 & -0.7264 & -0.7440 & -0.7456 & -1.0060 & -0.9954 & -0.8161 \\
\hline $\mathrm{H} 3 \mathrm{~b}$ & -0.9066 & -0.9457 & -0.7345 & -0.7547 & -0.7518 & -1.0070 & -1.0029 & -0.8257 \\
\hline Extra $\mathrm{H}$ & & & & & & & & -0.7282 \\
\hline Ow & & & & -22.0468 & -22.0269 & & & \\
\hline H1w & & & & -0.7291 & -0.7047 & & & \\
\hline $\mathrm{H} 2 \mathrm{w}$ & & & & -0.7264 & -0.7047 & & & \\
\hline
\end{tabular}




\section{Conclusion}

From the first experimental charge density on a thiosemicarbazide based complex compound and some quantum calculations, we have been able to point out some main results concerning the electrostatic properties of this compound.

i) According to the results of the electron density distribution and the topological analysis, the TSC ligand represents a highly delocalized system. The resonance effect particularly increases the amount of the negative charge and thus the donor abilities of the $\mathrm{S}$ atom. The coordination bond between $\mathrm{Zn}$ and $\mathrm{S}$ atoms is the result of the polarization of the torus shaped electron density of the free electron pair of the $\mathrm{S}$ atom toward the central metal ion. In contrast to $\mathrm{S}$, the free electron pair of $\mathrm{N}$ atom is clearly directed toward the $\mathrm{Zn}$ atom. The corresponding values of $\varrho$ at the BCP's are 0.52 and $0.41 \mathrm{e} . \AA^{-3}$, for $\mathrm{Zn}-\mathrm{N} 1$ and $\mathrm{Zn}-\mathrm{S} 1$ bonds, respectively. Both coordination bonds can be classified as polar covalent.

ii) The nine hydrogen bonds stabilize the crystal structure of $\left[\mathrm{Zn}(\mathrm{TSC})_{2}\right]\left(\mathrm{NO}_{3}\right)_{2}$. The structure also contains complementary hydrogen bonding intrinsically characteristic for the majority of TSC based supramolecular structures. The complementary hydrogen bonds are formed between the pair of donors from the complex cation and the nitrate oxygen atoms as acceptors. The complementary bonds slightly differ in their topological values. The lower amount of $\mathrm{Q}$ at the $\mathrm{BCP}$ is found in the case of bifurcated N3-H3a...O1 hydrogen bond. The topological characteristics of the O1-N4 and O2-N4 bond whose O atoms are involved in complementary hydrogen bonding are similar.

iii) The EP of the complex part of the molecule which is entering the supramolecular structures has been derived. The significantly high positive EP found in the region of the $\mathrm{Zn}$ atom suggests that the increase of coordination number of $\mathrm{Zn}$ (by coordination of the additional ligands) in the supramolecular complexes could be induced by this property. The theoretical calculations show that in the gas phase this nucleophilic zone is retained.

iv) The topologic features of the EP in the vicinity of the $\mathrm{Zn}$ atom confirm that the $\mathrm{Zn}-\mathrm{S}$ or $\mathrm{Zn}-\mathrm{N}$ 
bonds are weak bonds. Internal atoms like C1, N2 and N3 display a triangularly-shaped closed basins whereas peripheral $\mathrm{H} 2$, $\mathrm{H} 3 \mathrm{a}$ and $\mathrm{H} 3 \mathrm{~b}$ have extended basins.

v) The EPN values calculated by DFT method for the several TSC complexes entering the supramolecular structures show the identical sequence of the hydrogen reactivity toward the hydrogen bonding. These values suggest that in each of the complexes the hydrazine fragment N2-H2 shows the highest tendency to form the hydrogen bond; however the affinity of the other donor from the complementary pair is less pronounced. It can be suggested that the formation of the strongest, complementary hydrogen bonding in the crystal is rather a consequence of the suitable geometrical orientation of the $\mathrm{H} 2$ and $\mathrm{H} 3 \mathrm{a}$ atoms than their preferable reactivity. The EP at the hydrogen sites of the molecule retrieved from the crystal lattice reflects the present state of the hydrogen bonding regarding their strength.

\section{Acknowledgement}

The authors thanks Dr. B. Courcot (UMR 8580, actually post-doc at Prince of Wales Medical Research Institute of Sydney, Australia) for help and constructive discussions concerning the theoretical discussions. This work is as part of a project (co-directed by A. Spasojević-de Biré and G.A. Bogdanović) within the Franco-Serbian bilateral program "Pavle Savić 2006". S.B.N. and G.A.B thank the Ministry of Science of the Republic of Serbia for financial support (Projects Nos. 142010 and 142028).

Supporting Information Available: Crystallographic experimental details, fractional coordinates, atomic thermal parameters, $\varkappa, \varkappa^{\prime}, P_{\text {val }}$, and $P_{\operatorname{lm}}$ multipole parameters, geometrical parameters and additional residual and deformation density maps for both strategies used in the multipole refinement. This material is available free of charge via the Internet at http://pubs.acs.org. The deposition number of 
the supplementary crystallographic data is CCDC 653751

\section{References}

(1) Tapiero, H.; Tew, K. D. Biomedicine \& Pharmacotherapy, 2003, 57, 399.

(2) Lipscom, W. N.; Strater N. Chem. Rev. 1996, 96, 2375.

(3) Dudev, T.; Lim, C. J. Am. Chem. Soc. 2000, 122, 11146.

(4) Clark-Baldwin, K.; Tierney, D. L.; Govindaswamy, N.; Gruff, E. S.; Kim, C.; Berg, J.; Koch, S. A.; Penner-Hahn, J. E. J. Am. Chem. Soc. 1998, 120, 8401.

(5) a) Gómez Quiroga, G.; Navarro Ranninger, C. Coord. Chem.Rev., 2004, 248, 119; b) Casas, J. S.; García-Tasende, M. S.; Sordo, J. Coord. Chem.Rev. 2000, 209 197; c) Dittes, U.; Vogel, E.; Keppler, B. K. Coord. Chem.Rev. 1997, 163, 345; d) West, D. X.; Liberta, A. E.; Padhye, S. B.; Chikate, R. C.; Sonawane, P. B.; Kumbhar, A. S.; Yerande, R. G. Coord. Chem.Rev., 1993, 123, 49.

(6) (a) Beraldo, H. Quimica Nova 2004, 27, 461; (b) Beraldo, H.; Gambino, D. Mini-Rev. Med. Chem. $2004,4,31$.

(7) Cowley, A. R.; Davis, J.; Dilworth, J. R.; Donnelly, P. S.; Dobson, R.; Nightingale, A.; Peach, J. M.; Shore, B.; Kerr, D.; Seymour, L. Chem. Comm. 2005, 845.

(8) Kovala-Demertzi, D.; Yadav, P. N.; Wiecek, J.; Skoulika, S.; Varadinova, T.; Demertzis, M. A. J. Inorg. Biochem. 2006, 100, 1558

(9) a) Burrows, A. D.; Harrington, R. W.; Mahon, M. F.; Teat, S. J. CrystEngComm. 2005, 7, 388; b) Burrows, A. D.; Harrington, R. W.; Mahon, M. F.; Teat, S. J. Cryst.Growth Des. 2004, 4, 813; c) Burrows, A. D.; Harrington, R. W.; Mahon, M. F. Eur. J. Inorg. Chem. 2003, 766; d) Babb, J. E. V.; Burrows, A. D.; Harrington, R. W.; Mahon, M. F. Polyhedron, 2003, 22, 673; e) Burrows, A. D.; 
Harrington, R. W.; Mahon, M. F.; Teat, S. J. CrystEngComm. 2002, 22, 539; f) Burrows, A. D.; Harrington, R. W.; Mahon, M. F. CrystEngComm. 2000, 2, 77; g) Burrows, A. D.; Menzer, S.; Mingos, D. M. P; White, A. J. P.; Williams, D. J. J. Chem. Soc., Dalton Trans. 1997, 4237; h) Burrows, A. D.; Mingos, D. M. P.; White, A. J. P; Willams, D. J. Chem. Comm. 1996, 97.

(10) a) Li, S.-L.; Usman, A.; Razak, I.-A.; Fun, H.-K.; Wu, J.-Y.; Tian, Y.-P.; Jiang, M.-H.; Chen, Z.Y. Acta Cryst. 2003, C59, m181; b) Fun, H.-K.; Wu, J.-Y.; Tian, Y. -P.; Jiang, M.-H.; Chen, Z.-Y. Acta Cryst. 2003, E59, 199; (c) Novaković, S. B., Bogdanović, G. A., Leovac V. M. Inorg. Chem. Commun. $2005,8,9$.

(11) (a) Etter, M. C. Acc. Chem. Res. 1990, 23, 120; (b) Etter, M. C. J. Phys. Chem. 1991, 95, 4601.

(12) Sun, D.; Cao, R.; Liang, Y.; Shi, Q.; Hong, M. J. Chem. Soc., Dalton Trans 2001, 2335.

(13) a) Coppens, P. X-ray charge density and chemical bonding; Oxford University press 1997; b) Coppens, P. Acta Cryst. 1998, A54, 779 ; c) Koritsanszky, T. S.; Coppens, P. Chem. Rev. 2001, 101, 1583.

(14) Cotton, F. A.; Wilkinson, G. W. Advanced Inorganic Chemistry, Interscience Publishers, 1966, p. 610.

(15) O'Toole, N. J.; Streltsov, V. A. Acta Cryst., 2001, B57, 128.

(16) Lee, C.-R.; Wang, C.-C.; Chen, K.-C.; Lee, G.-H.; Wang, Y. J. Phys. Chem. A., 1999, $103,156$.

(17) Spasojević-de Biré, A.; Bouhmaida, N.; Kremenović, A.; Morgant, G.; Ghermani, N.-E. J. Phys. Chem. A. 2002, 106, 12170.

(18) a) Romanenko, G. V.; Saveleva, Z. A.; Larionov, S. V. Zh. Strukt. Khim. 1999, 40, 593; b) Tong, Y.-X.; Su, C.-Y.; Zhang, Z.-F.; Kang, B.-S.; Yu , X.-L.; Chen, X.-M. Acta Cryst. 2000, C56, 44. 
(19) Allen, F. H. Acta Cryst. 2002, B58, 380.

(20) Row, T. N. G; Desiraju, R. G. Acta Cryst. 2006, B62, 118.

(21) Novakovic, S. B.; Fraisse, B.; Bogdanovic, G. A.; Spasojevic-de Bire, A. Cryst. Growth Des. 2007, 7, 191.

(22) Bader, R. F. W. Atoms-in-Molecules: A Quantum Theory;Clarendon: Oxford, 1990.

(23) SMART (5.625), SAINT (6.02), SADABS (2.03)Data Collection and Processing Software for the SMART System.Siemens, (BRUKER-AXS) Analytical X-ray Instruments Inc., Madison.

(24) Blessing, R. H. J. Appl. Crystallogr. 1997, 30, 421.

(25) MOLLY program, Hansen, N. K.; Coppens, P. Acta Cryst., 1978, A34, 909.

(26) WINGX Program package for structure solution, Farrugia, L. J. J. Appl. Cryst. 1999, 32, 837.

(27) Kuhs, W. F. Acta Crystallogr. 1983, A39, 148.

(28) Allen, F.H., Kennard, O., Watson, D.G., J. Chem. Soc. Perkin Trans. 1997, S1.

(29) Frisch, M. J.; Trucks, G. W.; Schlegel, H. B.; Scuseria, G. E.; Robb, M. A.; Cheeseman, J. R.; Montgomery, J. A., Jr.; Vreven, T.; Kudin, K. N.; Burant, J. C.; Millam, J. M.; Iyengar, S. S.; Tomasi, J.; Barone, V.; Mennucci, B.; Cossi, M.; Scalmani, G.; Rega, N.; Petersson, G. A.; Nakatsuji, H.; Hada, M.; Ehara, M.; Toyota, K.; Fukuda, R.; Hasegawa, J.; Ishida, M.; Nakajima, T.; Honda, Y.; Kitao, O.; Nakai, H.; Klene, M.; Li, X.; Knox, J. E.; Hratchian, H. P.; Cross, J. B.; Bakken, V.; Adamo, C.; Jaramillo, J.; Gomperts, R.; Stratmann, R. E.; Yazyev, O.; Austin, A. J.; Cammi, R.; Pomelli, C.; Ochterski, J. W.; Ayala, P. Y.; Morokuma, K.; Voth, G. A.; Salvador, P.; Dannenberg, J. J.; Zakrzewski, V. G.; Dapprich, S.; Daniels, A. D.; Strain, M. C.; Farkas, O.; Malick, D. K.; Rabuck, A. D.; Raghavachari, K.; Foresman, J. B.; Ortiz, J. V.; Cui, Q.; Baboul, A. G.; Clifford, S.; Cioslowski, J.; 
Stefanov, B. B.; Liu, G.; Liashenko, A.; Piskorz, P.; Komaromi, I.; Martin, R. L.; Fox, D. J.; Keith, T.; Al-Laham, M. A.; Peng, C. Y.; Nanayakkara, A.; Challacombe, M.; Gill, P. M. W.; Johnson, B.; Chen, W.; Wong, M. W.; Gonzalez, C.; Pople, J. A. Gaussian 03, revision B.04; Gaussian, Inc.: Wallingford, CT, 2004.

(30) Andreetti, G. D.; Domiano, P.; Gasparri, G. F.; Nardelli, M.; Sgarabotto, P. Acta Cryst. 1970, $B 26,1005$.

(31) Coghi, L.; Lanfredi, A. M. M.; Tiripicchio, A. J.Chem.Soc.,Perkin Trans.2 1976, 1808.

(32) Steiner, T. Phys. Chem. A, 1998, 102, 7041.

(33) Ghermani, N. E.; Bouhmaida, N.; Lecomte, C. ELECTROS, STATDENS, FIELD+, POTNUC: Computer Program to Calculate Electrostatic Properties from high-resolution X-ray diffraction; Internal Report; UMR CNRS 7036, Université Henri Poincaré, Nancy 1, France, UMR CNRS 8612, Université Paris XI, France and Laboratoire LSM, Université Cadi Ayyad, Morocco (1992-2007).

(34) Souhassou, M. Atomic Properties from Experimental Electron Densities: Program Newprop-Int, 19th European Crystallographic Meeting, Nancy, France, August 25-31, 2000; Abstract S2-m2-p2, p 195 (also LCM3B Internal Report, Université Henri Poincaré, Nancy 1, France).

(35) Abramov, Y. A. Acta Cryst. 1997, A53, 457.

(36) (a) Destro, R.; Soave, R.; Barzaghi, M.; Presti L. L. Chem. Eur. J. 2005, 11, 4621; (b) Munshi, P.; Row, T. N. G. Acta Cryst. 2006, B62, 612; (c) Espinosa, E.; Molins, E.; Lecomte, C. ; Phys.Rev. 1997, B56, 1820. (d) Dahaoui, S.; Pichon-Pesme, V.; Howard, J. A. K.; Lecomte, C. J.Phys Chem. 1999, 103, 6240. (e) Lee, C. -R.; Tan, L. -Y.; Wang, Y. J. Phys.Chem. Solids, 2001, 62, 1613. (f) Pillet, S.; Souhassou, M.; Pontillon, Y.; Caneschi, A.; Gatteschi, D.; Lecomte. C. New J. Chem 2001, $25,131$. (g) Guillot, R.; Muzet, N.; Dahaoui, S.; Lecomte, C.; Jelsch, C. Acta Cryst. 2001, B57, 567. (h) Munshi, P.; Guru Row, T. N. Acta Cryst. 2002, B58, 1011. (i) Hambley, T. W., Hibbs, D. E.; Turner, P.; 
Howardb, S. T.; Hursthouse M. B. J. Chem. Soc., Perkin Trans. 2002, 2, 235. (j) Hibbs, D. E.; AustinWoods, C. J.; Platts, J. A.; Overgaard, J.; Turner P. Chem. Eur. J. 2003, 9, 1075. (k) Lee, C. R.; Tang, T. H.; Chen, L.; Wang Y. Chem. Eur. J. 2003, 9, 3112. (1) Ghermani, N. E.; Spasojević-de Biré, A.; Bouhmaida, N.; Ouharzoune, S.; Bouligand, J.; Layre, A.; Gref, R.; Couvreur, P. Pharm. Res., 2004, 21, 598. (m) Leusser, D.; Henn, J.; Kocher, N.; Stalke, D. J. Am. Chem. Soc. 2004, 126, 1871. (n) Wagner, A.; Flaig, R.; Dittrich, B. ; Schmidt, H.; Koritsanszky, T.; Luger P. Chem. Eur. J. 2004, 10, 2977. (o) Overgaard, J.; Hibbs D., E. Acta Cryst. 2004, B60, 480; (p) Tsirelson, V. G., Stash, A. I., Potemkin, V. A. Rykounov, A. A., Shutalev, A. D., Zhurova, E. A., Zhurov, V. V., Pinkerton, A. A., Gurskaya, G. V., Zavodnik, V. E., Acta Cryst. 2006 B62, 676.

(37) (a) Smith, G. T.; Mallinson, P. R.; Frampton C. S.; Howard J. A. K. J. Chem. Soc., Perkin Trans. 2, 1997, 1329; (b)Kozísek, J.; Hansen, N. K.; Fuess, H. Acta Cryst. 2002, B58, 463; (c) Lee, J. J.; Lee, G. H., Wang, Y. Chem. Eur. J. 2002, 1821; (d) Tafipolsky, M.; Scherer, W.; Ofele, K.; Artus, G.; Pedersen, B.; Herrmann, W. A.; McGrady, G. S., J. Am. Chem. Soc. 2002, 124, 5865; (e) Ritchie, J. P.; Zhurova, E. A.; Martin, A.; Pinkerton, A. A. J. Phys. Chem. B 2003, 107, 14576; (f) Zhurova, E. A.; Tsirelson, V. G.; Stash, A. I.; Yakovlev, M.V.; Pinkerton, A. A. J. Phys. Chem. B 2004, 108, 20173; (g) Zhurova, E. A.; Martin, A.; Pinkerton, A. A. J. Am. Chem. Soc. 2002, 124, 8741.

(38) (a) Iversen, B. B.; Larsen, F. K.; Figgis B. N.; Reynolds, P. A. J. Chem. Soc., Dalton Trans., 1997, 2227; (b) Hwang, T.-S.; Wang, Y. J. Phys. Chem. A 1998, 102, 3726; (c) Kozsek, J.; Hansen, N. K.; Fuess H. Acta Cryst. 2002, B58, 463; (d) Bytheway, I; Figgis, B. N.; Sobolev, A. N. J. Chem. Soc., Dalton Trans., 2001, 3285; (e) Macchi, P.; Schultz, A. J.; Larsen, F. K.; Iversen B. B. J. Phys. Chem. A 2001, 105, 9231; (f) Wang, C.-C.; Tang, T.-H.; Wang. Y. J. Phys. Chem. A 2000, 104, 9566; (g) Kozisek, J.; Fron, M.; Skubak, P.; Popkov, A.; Breza, M.; Fuess, H.; Paulmann, C. Acta Cryst. 2004, A60, 510; (h) Pillet, P.; Souhassou, M.; Mathoniere, C.; Lecomte, C. J. Am. Chem. Soc. 2004, 126, 1219; (i) Farrugia, L. J.; Frampton, C. S.; Howard, J. A. K.; Mallinson, P. R.; Peacock, R. D.; Smith, G. 
T.; Stewart, B. Acta Cryst. 2006, B62, 236.

(39) Espinosa, E.; Lecomte, C.; Molins, E. Chem. Phys. Lett. 1998, 285, 170.

(40) Portmann, S.; Lüthi, H. P. MOLEKEL: An Interactive Molecular Graphics Tool. Chimia 2000, $54,766$.

(41) Campbell, M. J. Coord Chem. Rev. 1975, 15, 279 and references therein.

(42) Chemical Applications of Atomic and Molecular Electrostatic Potentials. Politzer, P. Truhlar, D.G. Eds. Plenum, New York. (1981).

(43) Bouhmaida, N.; Dutheil, M.; Ghermani, N.E.; Becker P. J. Chem. Phys. B 2002, 116, 6196.

(44) Tsirelson, V. G.; Avilov, A. S.; Lepeshov, G. G. ; Kulygin, A. K.; Stahn, J. ; Pietsch, U.; Spence, J. C. H. J. Chem. Phys. B 2001, 105, 5068.

(45) Feynman, R. P. Phys. Rev. 1939, 56, 340; Hellmann, H. Einfuerung in die Quantum-chemie; Deuticke: Leipzig, 1937.

(46) Galabov, B.; Bobadova-Parvanova, P.; Ilieva, S.; Dimitrova, V. J. Molec. Struct. (Theochem) 2003, 630, 101 and references therein; b) Ferrante, F.; La Manna, G. J. Phys. Chem. A. 2003, 107, 91. c) Galabov, B.; Cheshmedzhieva; Ilieva, D.; Hadjieva, S. B. J. Phys. Chem. A, 2004, 108, 11457. d) Galabov, B.; Atanasov, Y.; Ilieva, S.; Schaefer, H. F. J. Phys. Chem. A, 2005, 109, 11470. 